\title{
GEAR RATTLE DYNAMICS: LUBRICANT FORCE FORMULATION ANALYSIS ON STATIONARY CONDITIONS
}

\author{
A. Fernandez-del-Rincon, A. Diez-Ibarbia, M. Iglesias, F. Viadero \\ Department of Structural and Mechanical Engineering, University of Cantabria. Avda. \\ de los Castros s/n 39005 Santander, Spain.
}

\begin{abstract}
Gear rattle is a common and inherent phenomenon to multi-stage-constantmesh gearboxes, since this kind of transmission consist of two different types of gear pairs: active and inactive stages. The former is in charge of transmitting the energy, whilst the latter, although its teeth are engaged, is loosely connected to the output shaft. Gear rattle problematic resides in undesirable impacts and fluctuations in the inactive gears provoked by their interaction with the active stage, leading to vibrations which can produce fails in elements connected or belonging to the gearbox. In this regard, understanding the lubricant role is crucial, being this aspect the key to comprehend the dynamic behaviour of low-loaded gear transmissions and to palliate these phenomenon consequences as the ultimate goal of this research. Within this context, in this work, six formulations, which consider both entraining and squeeze fluid effects, were implemented in gear transmission models previously developed by the authors in order to calculate the hydrodynamic forces. Special attention was paid to the fluid viscosity influence on the dynamic behaviour under stationary conditions.
\end{abstract}

Keywords: Gear Rattle, Hydrodynamic lubrication, Vibrations

\section{Introduction}

Gearboxes are one of the key elements of the automobile powertrain $[7,16,20,21]$, which main goal is to transform the energy provided by the engine to wheels' speed or torque, depending on the driver's needs during the vehicle travel. Although gearboxes are principally known because of this 
application, they are also used in helicopters, electric windmills, tractors and so on $[3,17,18,22]$. Currently, one of the most used gearboxes is the one which stages are constantly in mesh, choosing the gear by synchronizers, and therefore, avoiding displacement between gears to get in mesh, as occurred in old-fashioned gearbox configurations. In this regard, constant mesh transmissions consist of two different gear pairs, the ones which are actually transmitting the power and those which are not, but are engaged. The former are known as "active" and the latter are usually called "inactive". This gearbox configuration results in a dynamic issue derived from the interaction of the active and inactive stages known as gear rattle, which usually leads to undesirable noise and harmful vibrations to the components connected or belonging to the gearbox.

Since gearboxes are lubricated, the role of the fluid is of key importance to understand and avoid gear rattling, as it is the only element that can palliate the impacts and fluctuations between teeth. Ideally, increasing the fluid viscosity would solve this issue, however, it has to be taken into account the power losses derived from an uncontrolled viscosity increment in addition to the variation of dynamic system features. In this respect, finding the lubricant viscosity which eludes gear rattle without decreasing the gearbox performance is the engineering challenge in this application. On this matter, it is required to accurately model damping mechanisms linked to the lubricated contact, since they have received little attention in contrast to the large number of studies on gear dynamics [1, 4, 5, 23, 24].

In order to model the fluid action in rattle conditions, there are few approaches in the scientific literature $[2,14,15,25,26,27,28,29]$, which results show some dispersion, not existing a unified solution. As commented, the impacts occur on the inactive gears due to the fact that they are lowly loaded, and therefore, the vibrations produced in the active gear pair greatly affects them. In this context, the lubrication regime present in the inactive gear conjunctions is hydrodynamic, being several the effects which, in combination, produce the fluid action. Particularly, this action is commonly calculated by the superposition of two effects [26, 27, 28, 29], although there are approaches which consider only one of them $[2,13,14,15]$; the fluid squeeze when teeth profiles are approaching and the entraining velocity of the lubricant in the conjunction. From previous preliminary results [10], it was concluded that both effects are required to model properly the lubricant action in hydrodynamic conditions. This is the reason why, continuing that preliminary study, this work assesses a gear pair dynamic behaviour in rattle conditions for dif- 
ferent fluid viscosities, restricting the formulations to those which consider both squeeze and entraining fluid effects. The strength of this proposal lies in the use of an enhanced model previously developed by the authors [8, 11, 12], which takes into account flank and counter-flank contacts, in which six hydrodynamic formulations were implemented with the aim of providing the results which could lead to a unified formulation of hydrodynamic efforts.

After this introduction, section 2 presents the fundamentals required to develop and understand the six hydrodynamic force formulations implemented. Then, the transmission dynamic model features are described in section 3, where the used formulations are reorganized to facilitate the reader comprehension. In section 4 , it is described the main parameters of the gear transmission case of study and the the set-up of the performed studies. Afterwards, the results are discussed, to finish with some conclusions in the last section.

\section{Fundamentals of hydrodynamic lubrication}

The use of lubricant fluid is common in gear transmissions, in order to avoid dry contact and overheating which could lead to power losses and premature system fails. In lubrication theory, depending on the transmitted load, rheological properties and the gears roughness, the regimes of lubrication are generally divided into: Elasto-Hydrodynamic Lubrication $(E H L)$, viscous rigid, iso-viscous elastic and Hydrodynamic Lubrication (HDL) [9].

Regarding vehicle gearboxes, the inactive stages are usually under $H D L$, which analysis is the main aim of this work since it is focused on gear rattle, whilst the active gear is generally under EHL (Figure 1).

In order to identify among regimes of lubrication, in this study, the Greenwood (equation (1)) and the Stribeck's parameters were used to assure that the transmission was on $H D L$.

$$
\left.\begin{array}{c}
G_{e}=\frac{(2 W)^{8 / 3}}{(2 U)^{2}} \\
G_{v}=\frac{G W^{3}}{U^{2}}
\end{array}\right\} \rightarrow \begin{gathered}
W=\frac{q}{2 \cdot 10^{9} E_{e q} \rho_{e q}}, \quad U=\frac{2 V_{e} \eta}{2 \cdot 10^{9} E_{e q} \rho_{e q}} \\
G=2 \alpha E_{e q}
\end{gathered}
$$

Where $W, U$ and $G$ are non-dimensional parameters respectively related to the load, rheological and material properties, which are dependant of the 


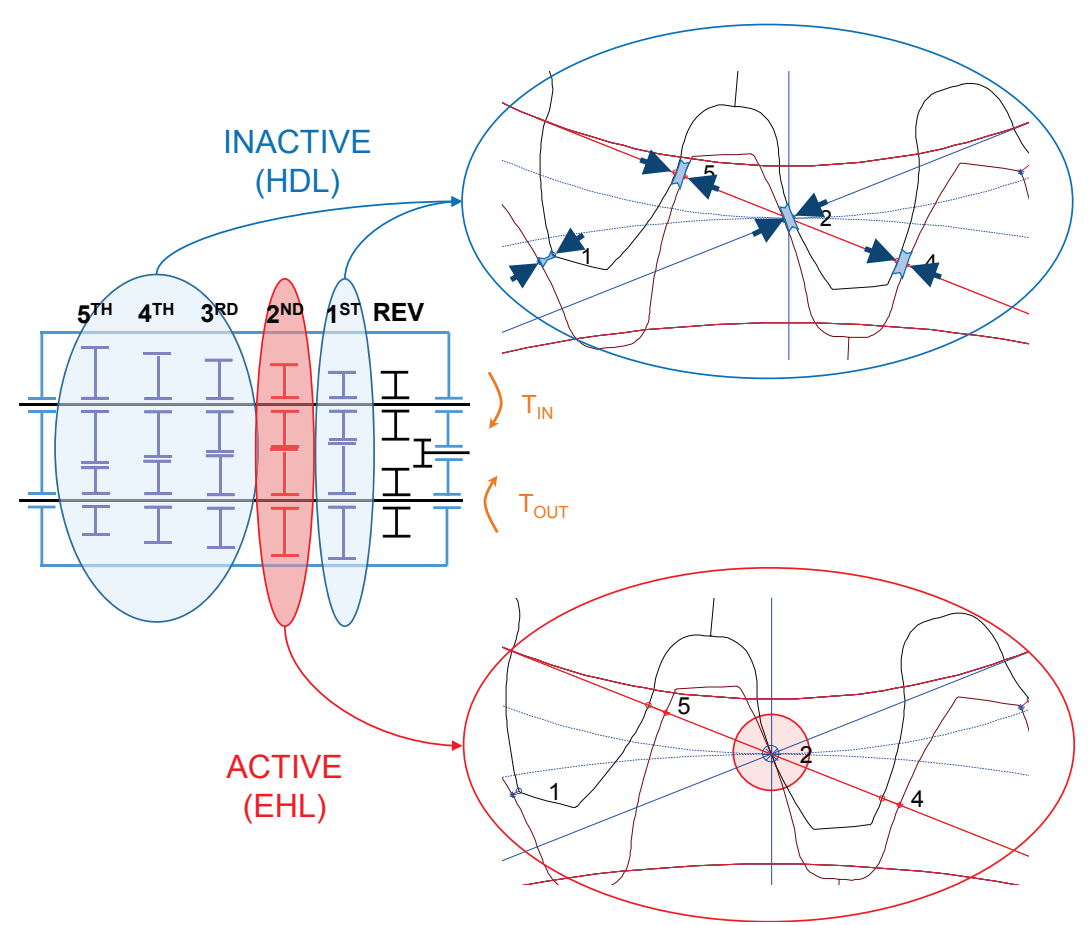

Figure 1: Schema of the most common lubrication regimes present in a gearbox

Young modulus $\left(E_{e q}\right)$, the oil dynamic viscosity $\left(\eta_{\text {oil }}\right)$, the fluid entraining velocity $\left(V_{e}\right)$, the load per unit of length $(q)$, the equivalent radius of curvature $\left(\rho_{e q}\right)$ and the viscosity-pressure coefficient $(\alpha)$. Moreover, the Stribeck parameter is dependant of the central film thickness $h_{c}$ and inversely proportional to the mean roughness of the gear profiles $R_{a}\left(\lambda=h_{c} / R_{a}\right)$.

After determining the lubrication regime, the fluid effect on the line of action is obtained by Kelvin-Voigt's model, which calculates the lubricant force by means of multiplying a linear viscous damping and the approaching velocity (equation 2).

$$
F_{C}=C_{l u b} \dot{\delta}
$$

For the analytical calculation of this viscous damping $\left(C_{l u b}\right)$ and to assess the considered fluid effects, solving the Reynolds equation was required (equation 3), in addition to the comprehension of the terms which compose this well-known equation. 


$$
\underbrace{\frac{\partial}{\partial x}\left(\frac{\rho h^{3}}{12 \eta} \frac{\partial p}{\partial x}\right)}_{\text {Poiseulle }}=\underbrace{\frac{\partial}{\partial x}\left(\frac{\rho h\left(u_{1}+u_{2}\right)}{2}\right)}_{\text {Couette }}+\underbrace{\rho \frac{\partial h}{\partial t}}_{\text {Squeeze }}+\underbrace{h \frac{\partial \rho}{\partial t}}_{\text {Local expansion }}
$$

Where $p$ is the fluid pressure distribution, $\rho$ the density, $h$ the film thickness, $u_{i}$ are the profile velocities in the $x$ direction (tangential to the teeth profile) and $\dot{h}=\frac{\partial h}{\partial t}$ represents the speed when the contact profiles are approaching or moving away, being negative when they are approaching.

At the same time, Couette term involves several effects expressed in equation 4:

$$
\underbrace{\frac{\partial}{\partial x}\left(\frac{\rho h\left(u_{1}+u_{2}\right)}{2}\right)}_{\text {Couette }}=\underbrace{\rho \frac{\left(u_{1}+u_{2}\right)}{2} \frac{\partial h}{\partial x}}_{\text {Wedge }}+\underbrace{h \frac{\left(u_{1}+u_{2}\right)}{2} \frac{\partial \rho}{\partial x}}_{\text {Density wedge }}+\underbrace{\frac{\rho h}{2} \frac{\partial\left(u_{1}+u_{2}\right)}{\partial x}}_{\text {Lengthening wedge }}
$$

Regarding these two equations 3 and 4, as the regime of lubrication is $H D L$, some approximations can be performed in order to simplify them. For instance, the lubricant rheological properties could be considered to be constant in the conjunction, and therefore, the "Local expansion" and "Density wedge" terms can be neglected under these conditions $(\rho(x, y, z, t) \equiv \rho)$. Moreover, another term which could be ignored is the "Lengthening wedge", since the contact length is in the order of a few microns [6], thus, the sum of the profile velocities can be approximated as constant on the contact area. Including these two approximations, Reynolds equation is simplified to the form presented in equation 5 .

$$
\underbrace{\frac{\rho}{12 \eta} \frac{\partial}{\partial x}\left(h^{3} \frac{\partial p}{\partial x}\right)}_{\text {Poiseulle }}=\underbrace{\rho \frac{\left(u_{1}+u_{2}\right)}{2} \frac{\partial h}{\partial x}}_{\text {Wedge }}+\underbrace{\rho \frac{\partial h}{\partial t}}_{\text {Squeeze }}
$$

Hence, two effects are involved: the physical wedge, which is associated with the oil inlet and outlet into the contact area, and the squeeze effect of the oil trapped between normal approaching surfaces.

The last step in order to calculate the hydrodynamic forces is to integrate the Reynolds equation, obtaining the pressure distribution on the contact area. Depending on the simplifications considered and the boundary conditions, several analytical expressions can be found in the literature $[2,14,15,27,28,29]$. In this respect, even though the formulations assessed 
in this work consider both effects (wedge and squeeze), the authors also differ in two aspects when calculate their expressions: i) the calculation of the pressure distribution and ii) the contact area length. Regarding the former, the formulations diverge in the pressure distribution shape, not to mention the boundary conditions. With respect to the latter, some formulations consider an infinite contact area, whilst in others different finite values are assumed.

With all the above in mind, the force due to the lubricant in the considered domain $\left(x_{0}<x<x_{1}\right)$ can be calculated as:

$$
F_{H D L}=b \int_{x_{0}}^{x_{1}} p(x) d x=F_{\text {Wedge }}+F_{\text {Squeeze }}=C_{e q}^{\text {Wedge }} V_{e}-C_{e q}^{\text {Squeeze }} \dot{h}
$$

Where $b$ is the gear face width.

Next, it is presented a description of the hydrodynamic force formulations which were analysed in this work, in addition to their approaches in terms of pressure distribution, boundary conditions and contact area extension.

\subsection{Sasaki et al. formulation}

Sasaki et al. proposed an expression where wedge and squeeze terms were superposed. This means that each effect was calculated individually [26, 28].

In order to obtain the wedge effect, the solution was calculated using the Half-Sommerfeld boundary conditions, which impose a pressure maximum at $x_{a}$ (equation 7 ).

$$
\left.\begin{array}{ll}
\frac{\partial p}{\partial x}=0 & \rightarrow x=-x_{a} \\
p=0 & \rightarrow x=-\infty
\end{array}\right\}
$$

Calculating the hydrodynamic force due to the physical wedge taking into account an infinite contact area:

$$
F_{H D L}^{W e d g e}=b \int_{-\infty}^{\infty} p(x) d x \Rightarrow C_{e q}^{W e d g e}=2 b \eta \frac{\rho_{e q}}{h_{c}}
$$

When the squeeze term was calculated, the imposed boundary conditions were that the pressure was null at $\pm \infty$. This fact leads to a symmetric pressure distribution without negative values (equation 9).

$$
\left.\begin{array}{ll}
\frac{\partial p}{\partial x}=0 & \rightarrow x=0 \\
p=0 & \rightarrow x= \pm \infty
\end{array}\right\}
$$


Afterwards, the force was calculated by integrating between $\pm \infty$ the pressure distribution:

$$
\begin{gathered}
F_{H D L}^{\text {Squeeze }}=b \int_{-\infty}^{\infty} p(x) d x \\
\Rightarrow C_{e q}^{\text {Squeeze }}=\frac{3 \sqrt{2} \pi b \eta}{2}\left(\frac{\rho_{e q}}{h_{c}}\right)^{\frac{3}{2}}\left[1-\frac{2}{\pi} \arctan \left(\frac{3 \sqrt{2}}{2} \sqrt{\frac{\rho_{e q}}{h_{c}}} \frac{\dot{h}}{V_{e}}\right)\right]
\end{gathered}
$$

\subsection{Sasaki-modified formulation}

Following Wiegert et al. work [28], a modification of the Sasaki's formulation was implemented in order to calculate the hydrodynamic force. Specifically, the Sasaki's model was improved by including Martin's consideration [19], which has been experimentally proven to fulfill the static conditions of the hydrodynamic force [28]. This improvement consists of considering a $\sqrt{6}$ instead of a 2 in the term due to fluid inflow (wedge effect):

$$
F_{H D L}^{W e d g e}=b \int_{-\infty}^{\infty} p(x) d x \Rightarrow C_{e q}^{W e d g e}=\sqrt{6} b \eta \frac{\rho_{e q}}{h_{c}}
$$

The squeeze term was defined as previously presented in equation 10 .

\subsection{Rahnejat et al. formulation}

Rahnejat et al. followed the same approach as Sasaki et al., obtaining individually both wedge and squeeze effects. As a matter of fact, when the wedge term was solely calculated, the same solution as Sasaki's formulation is obtained (equation 8), since the Half-Sommerfeld boundary conditions were considered (equation 7).

Regarding the squeeze effect, a symmetric quadratic pressure distribution was considered, whilst the boundary conditions were that the pressure is zero at $\pm \infty$ (equation 12).

$$
\left.\begin{array}{ll}
\frac{\partial p}{\partial x}=0 & \rightarrow x=0 \\
p=0 & \rightarrow x= \pm \infty
\end{array}\right\}
$$

Then, the pressure distribution was integrated in the interval of $\pm \infty$ (equation 13).

$$
F_{H D L}^{\text {Squeeze }}=b \int_{-\infty}^{\infty} p(x) d x \Rightarrow C_{e q}^{\text {Squeeze }}=\frac{3 \sqrt{2} \pi b \eta}{2}\left(\frac{\rho_{\text {eq }}}{h_{c}}\right)^{\frac{3}{2}}
$$


An important aspect to remark about this formulation is that Rahnejat et al. considered only the wedge term when the profiles were moving away $(\dot{h}>0)$, considering both effects (wedge and squeeze) when the profiles were approaching $(\dot{h}<0)$.

\subsection{Rahnejat-modified formulation}

Following the same procedure as in section 2.2, it is proposed to improve Rahnejat's formulation by including the experimentally proved Martin's consideration [19]. Thus, the wedge term is defined by equation 11 whilst the squeeze term is determined as in Rahnejat et al. proposed (equation 13)

\subsection{Wiegert formulation}

Wiegert et al. proposed a semi-analytical expression which depends on the film rupture position $\left(x_{f r}\right)$ and the film thickness in that position $\left(h_{f r}\right)$, which both are usually numerically calculated [28, 29].

$F_{H D L}=3 \pi b \eta \frac{\rho_{e q}}{h_{f r}} V_{e}-3 \pi b \eta\left(\frac{\rho_{e q}}{h_{c}}\right)^{\frac{3}{2}}\left[\frac{\pi}{\sqrt{2}}+\frac{x_{f r}}{h_{f r}} \sqrt{\frac{h_{c}}{\rho_{e q}}}+\sqrt{2} \arctan \left(\frac{x_{f r}}{\sqrt{2 \rho_{e q} h_{c}}}\right)\right] \dot{h}$

In order to avoid the numerical calculation of the film rupture location and thickness, Wiegert et al. proposed two formulae depending on the required accuracy, in which procedure, instead of superposing both effects, the authors took into account the wedge and squeeze effects at the same time to calculate the force in the conjunction, in addition to Martin's consideration.

The first proposed formulation gives a relative error lower than $2 \%$ (equation 15), whilst the second's error is lower than $20 \%$ (equation 16):

$$
\begin{gathered}
F_{H D L}=\sqrt{6} \pi b \eta \frac{\rho_{e q}}{h_{c}} V_{e}-\frac{3 \sqrt{2} \pi b \eta}{2}\left(\frac{\rho_{e q}}{h_{c}}\right)^{\frac{3}{2}}\left[1-\frac{2}{\pi} \arctan \left(\sqrt{3} \sqrt{\frac{\rho_{e q}}{h_{c}}} \frac{\dot{h}}{V_{e}}\right)\right]_{(15} \dot{h} \\
F_{H D L}=\sqrt{6} \pi b \eta \frac{\rho_{e q}}{h_{c}} V_{e}-\frac{3 \sqrt{2} \pi b \eta}{2}\left(\frac{\rho_{e q}}{h_{c}}\right)^{\frac{3}{2}}\left[1-\frac{\sqrt{3} \pi \dot{h}}{\left(2 V_{e} \sqrt{\frac{h_{c}}{\rho_{e q}}}+\sqrt{3} \pi|\dot{h}|\right)}\right] \dot{h}
\end{gathered}
$$


In this respect, Wiegert et al. proposed the second formulation, even if the error was higher than the first one, in order to avoid the computational problems derived from the use of the $\arctan (x)$ function.

\section{Dynamic model description}

The hydrodynamic formulations presented in section 2 have been implemented in the gear transmission model previously developed by the authors $[8,11,12]$. Since the aim of this work is to study and assess the behaviour of these formulations under gear rattle conditions, a reduced model of 2 degrees of freedom (d.o.f) were used, although this model allows for using more d.o.f. when bearings and more gear pairs are considered [11]. These two d.o.f corresponded to the rotation of each wheel $\left(\theta_{1 R 1}\right.$ and $\left.\theta_{2 R 1}\right)$ and the dynamic equations of this 2-dof model can be synthesised as described in equation 17 .

$$
J_{j R k} \ddot{\theta}_{j R k}+t_{j R k \theta}\left(\theta_{j R k}, \theta_{j R k}\right)=T_{j R k} \quad \text { where } \quad\left\{\begin{array}{l}
j=1,2 \\
k=1
\end{array}\right.
$$

In subscript ${ }_{j R k}, j$ is the shaft number and, as there are two shafts, takes values of 1 and $2, R$ means that is rotational and $k$ is the wheel number, being 1 since there is only one gear per shaft. Moreover, $J$ is the inertia, $\theta$ the rotational degree of freedom, $t$ the torque due to the forces in the conjunction, whilst $T$ represents the external applied torque.

The inputs of this dynamic model were the pinion speed $\dot{\theta}_{1 R 1}$ and the resistive torque of the driven wheel $T_{2 R 1}$, which values are being specified in the following section, obtaining as results the driven wheel rotation $\theta_{2 R 1}$, which can be represented by the dynamic transmission error, and the torque due to the contact forces $\left(t_{j R k \theta}\right)$ required to overcome the resistive torque.

To calculate $t_{j R k \theta}$, it was necessary to determine the distances between gear teeth potentially in contact $\delta_{i}$, where $i$ is the number of each potential contact, which in turn allows for the calculation of the forces in the conjunction $F_{i}$. These forces $F_{i}$ were obtained differently depending on the lubrication regime of the considered contact and on the distance between teeth (equation 18). During this process, the model considers several aspects that modify this distance between profiles, such as manufacturing errors, tip and bottom reliefs among other parameters, in addition to flank and counterflank contacts. 


$$
F_{i}= \begin{cases}F_{H D L_{i}} & \delta_{i}>0 \\ F_{E H L_{i}} & \delta_{i} \leq 0\end{cases}
$$

From equation 18, it can be observed that two approaches were taken into account to calculate the contact force, and also, that there was not a transition region between elastohydrodynamic and hydrodynamic lubrication, which in general could lead to an error. However, since low-torque operating conditions were analysed, this assumption produces a negligible error. Regarding the calculation of contact forces, when the distance between tooth profiles was negative $\left(\delta_{i} \leq 0\right)$, the force $F_{E H L_{i}}$ was calculated by multiplying the magnitude of interference $\left(\delta_{i}\right)$ by its corresponding meshing stiffness $\left(K_{e q_{i}}\right)$, which in this study was obtained from a previous quasi-static analysis, although it can be calculated by a hybrid method of calculating the flexibility matrix superposing a global FEM model and a hertzian analytical expression. The procedure to calculate this force has been extensively explained by the authors in the literature, and for the sake of brevity, the reader interested in this procedure is referred to $[8,11,12]$. Nevertheless, when the distance between tooth profiles was positive $\left(\delta_{i}>0\right)$, the force $F_{H D L_{i}}$ was analytically calculated by the hydrodynamic equations presented in section 2, which are reorganised as presented in equation 19.

$$
F_{H D L_{i}}=\left\{\begin{array}{ll}
C_{e q_{i}}^{W e d g e} V_{e_{i}}-C_{e q_{i}}^{\text {Squeeze }} \dot{h_{i}} & \dot{h_{i}}<0 \\
C_{e q_{i}}^{W e d g e} V_{e_{i}} & \dot{h_{i}} \geq 0
\end{array}\right\}
$$

As can be seen, the squeeze effect forces are neglected when the profiles are moving away $\left(\frac{\partial h}{\partial t}>0\right)$, since the proposed formulations does only explain this physical effect when the profiles are approaching $\left(\frac{\partial h}{\partial t}<0\right)$. Table 1 lists the expressions of the implemented hydrodynamic force in the form of equation $19\left(C_{e q_{i}}^{\text {Wedge }}\right.$ and $\left.C_{\text {eqi }}^{\text {Squeeze }}\right)$.

To avoid an infinite value of the hydrodynamic force formulations when $h_{c}$ becomes null, a saturation value was adopted $\left(h_{\min }=10 R_{a}\right)$. This means that when the distance between profiles was smaller than $h_{\min }$, in order to calculate the hydrodynamic force, the central film thickness was equal to this saturation value $\left(h_{c}=h_{\min }\right)$. Moreover, when the profiles were far from each other, the force due to the lubricant was considered negligible. Specifically, it was assumed that this lubricant effect was negligible when the distance between profiles was higher than $1 \mathrm{~mm}\left(h_{c}>h_{\max }=1 \mathrm{~mm}\right)$. In order 
Table 1: $C_{e q_{i}}^{W e d g e}$ and $C_{e q_{i}}^{S q u e e z e}$ expressions for hydrodynamic force

\begin{tabular}{c||c||c}
\hline Formula & $C_{e q_{i}}^{\text {Wedge }}$ & $C_{\text {eq }}^{\text {Squeeze }}$ \\
\hline $\begin{array}{c}\text { Sasaki } \\
\text { Sasaki- } \\
\text { mod }\end{array}$ & $2 b \eta \frac{\rho_{e q}}{h_{c}}$ & $\frac{3 \sqrt{2} \pi b \eta}{2}\left(\frac{\rho_{e q}}{h_{c}}\right)^{\frac{3}{2}}\left[1-\frac{2}{\pi} \arctan \left(\frac{3 \sqrt{2}}{2} \sqrt{\frac{\rho_{e q}}{h_{c}}} \frac{\dot{h}}{V_{e}}\right)\right]$ \\
Rahnejat & $\sqrt{6} b \eta \frac{\rho_{e q}}{h_{c}}$ & $\frac{3 \sqrt{2} \pi b \eta}{2}\left(\frac{\rho_{e q}}{h_{c}}\right)^{\frac{3}{2}}\left[1-\frac{2}{\pi} \arctan \left(\frac{3 \sqrt{2}}{2} \sqrt{\frac{\rho_{e q}}{h_{c}}} \frac{\dot{h}}{V_{e}}\right)\right]$ \\
$\begin{array}{c}\text { Rahnejat- } \\
\text { mod }\end{array}$ & $\sqrt{6} b \eta \frac{\rho_{e q}}{h_{c}}$ & $\frac{3 \sqrt{2} \pi b \eta}{2}\left(\frac{\rho_{e q}}{h_{c}}\right)^{\frac{3}{2}}$ \\
Wiegert $_{0.02}$ & $\sqrt{6} b \eta \frac{\rho_{e q}}{h_{c}}$ & $\left.\frac{3 \sqrt{2} \pi b \eta \eta}{2}\left(\frac{\rho_{e q}}{h_{c}}\right)^{\frac{\rho_{e q}}{h_{c}}}\right)^{\frac{3}{2}}\left[1-\frac{2}{\pi} \arctan \left(\sqrt{3} \sqrt{\frac{\rho_{e q}}{h_{c}}} \frac{\dot{h}}{V_{e}}\right)\right]$ \\
Wiegert $_{0.2}$ & $\sqrt{6} b \eta \frac{\rho_{e q}}{h_{c}}$ & $\frac{3 \sqrt{2} \pi b \eta}{2}\left(\frac{\rho_{e q}}{h_{c}}\right)^{\frac{3}{2}}\left[1-\frac{\sqrt{3} \pi \dot{h}}{\left(2 V_{e} \sqrt{\frac{h_{c}}{\rho_{e q}}}+\sqrt{3} \pi|\dot{h}|\right)}\right]$ \\
\hline
\end{tabular}

to comprehend the force algorithm choice, Figure 2 represents the different regions when two teeth are contacting, which is also summarised in equation 20 .

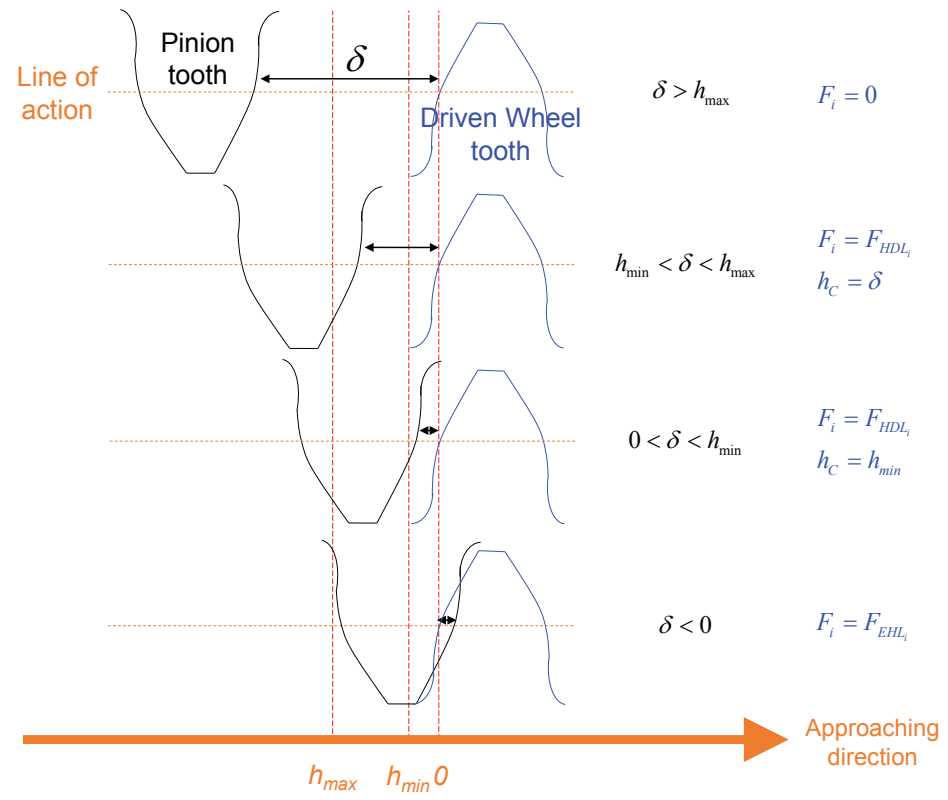

Figure 2: Schema of the force algorithm choice 


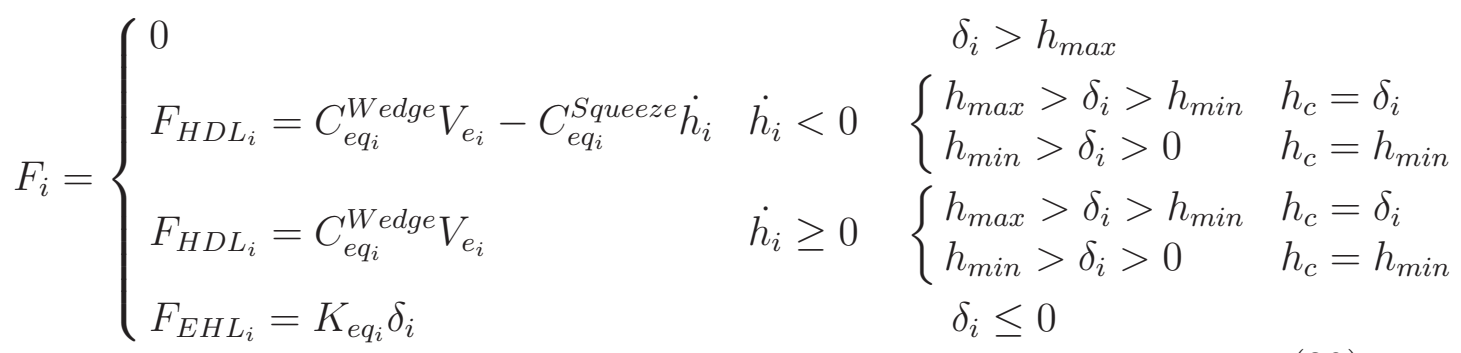

\section{Case of study and test set-up}

Table 2 shows the parameters of the transmission example of application, of which the dynamic behaviour was simulated.

Table 2: Gear transmission parameters

\begin{tabular}{cccc}
\hline Parameter & Value & Parameter & Value \\
\hline Pinion/Wheel teeth & $18 / 36$ & $\begin{array}{c}\text { Pinion/Wheel inertia } \\
\left(J_{1 R 1} / J_{2 R 1}\right)\left[\mathrm{kgm}^{2}\right]\end{array}$ & $\begin{array}{c}1.75 \mathrm{e}-4 \\
/ 2.8 \mathrm{e}-3\end{array}$ \\
$\begin{array}{c}\left(z_{1} / z_{2}\right) \\
\text { Rack Ad./Ded. }\end{array}\left(A d_{\text {rack }} / D d_{\text {rack }}\right)$ & $1.25 \mathrm{~m} / 1 \mathrm{~m}$ & Rack tip rad. $\left(r_{t}\right)$ & $0.25 \mathrm{~m}$ \\
$h_{\min } / h_{\max }[\mathrm{mm}]$ & $8 \mathrm{e}-3 / 1$ & Mean roughness $\left(R_{a}\right)[\mu \mathrm{m}]$ & 0.8 \\
Module $(\mathrm{m})[\mathrm{mm}]$ & 3 & Face width $(b)[\mathrm{mm}]$ & 26.7 \\
Poisson coef. $(\psi)$ & 0.3 & Pres. angle $\left(\varphi_{i}\right)[$ degree $]$ & 20 \\
Young modulus $(E)[G P a]$ & 207 & Half-width contact $(a) /$ & $1 / 1.355$ \\
Bearing radius $\left(r_{b}\right)[\mathrm{mm}]$ & 10 & Backlash $[\mathrm{mm}]$ & 81.1 \\
Radial clearance $\left(r_{c}\right)[\mathrm{mm}]$ & 0.025 & Bearing length $\left(l_{b}\right)[\mathrm{mm}]$ & 15 \\
\hline
\end{tabular}

As commented before, the model requires to introduce some input data. In this study, the pinion angular speed $\dot{\theta}_{1 R 1}$ and the resistive torque of the driven wheel $T_{2 R 1}$ were specified. Specifically, since stationary conditions of the system were to be assessed, the pinion angular speed was considered without excitation (equation 21), analysing the dynamic behaviour after some meshing cycles.

$$
\dot{\theta}_{1 R 1}=\Omega+\vartheta \sin (\Delta \omega t) \text { where } \vartheta=0
$$


The range of constant pinion speeds introduced was $\Omega=500: 100: 9000$ rpm, obtaining the dynamic transmission error after one thousand meshing cycles. This value was chosen because the gear pair achieved its stationary state. Moreover, in order to assess the different hydrodynamic formulations as well as the torque influence on the transmission dynamic behaviour, these pinion speeds were simulated under four scenarios of the resistive torque (Table 3).

Table 3: Resistive torque scenarios

\begin{tabular}{cc}
\hline Scenario & Torque value \\
\hline 1 & $T_{2 R 1}=0 \mathrm{Nm}$ \\
2 & $T_{2 R 1}=\frac{\pi \eta l_{b} r_{b}^{3}}{2 r_{c}} \dot{\theta}_{2 R 1}$ \\
3 & $T_{2 R 1}=0.1 \mathrm{Nm}$ \\
4 & $T_{2 R 1}=0.1+\frac{\pi \eta l_{b} r_{b}^{3}}{2 r_{c}} \dot{\theta}_{2 R 1}$ \\
\hline
\end{tabular}

In the first scenario, no torque was applied. In the second, the torque applied on the driven wheel was formulated as a torsional viscous damping, which simulates a journal bearing behaviour [27], where $\eta_{b}$ is the dynamic viscosity (same oil as in the gears $\eta_{b}=\eta$ ) $, r_{b}, l_{b}$ and $r_{c}$ are the journal bearing radius, width and radial clearance. This variable torque expression follows Petrov's friction, which is the typical resistance in low-load conditions of a gear mounted on a shaft by a journal bearing. Moreover, the resistive torque adopted a constant value in the third scenario, high enough to be close to EHL conditions, whilst in the fourth, the superposition of the two previous scenarios was performed. In this way, the dynamic system behaviour was assessed under no torque, only variable and only constant torque independently, and lastly, under the superposition of the constant and variable components.

These tests were performed when two dynamic viscosities were considered. In this respect, 75W90 lubricant oil model, which is commonly used in vehicle transmissions, was implemented (equation 22) [30]. 


$$
\eta=\rho \nu\left\{\begin{array}{l}
\rho=C_{1}+C_{2}\left(T_{i n}-40\right) \\
\left.\nu=Z-\exp \left(-0.7489-3.295 Z+0.6119 Z^{2}-0.3193 Z^{3}\right)\right)
\end{array}\right.
$$

$$
\text { Where } \begin{aligned}
Z & =\xi-0.7 \\
\log [\log (\xi)] & =C_{3}-C_{4} \log \left(T_{\text {in }}+237.15\right)
\end{aligned}
$$

Where the constants of the lubricant oil model were defined as $C_{1}=$ 0.8353, $C_{2}=-0.0006, C_{3}=7.9737$ and $C_{4}=3.0773$. As observed in equation 22, this model takes into account the effect of the temperature $\left(T_{i n}\right)$ on the rheological properties, where $\rho, \nu$ and $\eta$ are the density, the kinematic and dynamic viscosity of the fluid. These rheological parameter values for the two assessed lubricant temperatures $\left(40\right.$ and $60{ }^{\circ} \mathrm{C}$ ) are listed in Table 4.

Table 4: Gear transmission parameters

\begin{tabular}{cccc}
\hline $75 \mathbf{W 9 0}$ & $\begin{array}{c}\text { Density } \\
{\left[\mathrm{kg} / \mathrm{m}^{3}\right]}\end{array}$ & $\begin{array}{c}\text { Kinematic } \\
\text { viscosity }\left[\mathrm{m}^{2} / \mathrm{s}\right]\end{array}$ & $\begin{array}{c}\text { Dynamic } \\
\text { viscosity }[\text { Pas }]\end{array}$ \\
\hline$T_{\text {in }}=40^{\circ} \mathrm{C}$ & 835.9 & $9.594 \mathrm{e}-05$ & 0.08 \\
$T_{\text {in }}=60^{\circ} \mathrm{C}$ & 823.3 & $4.144 \mathrm{e}-05$ & 0.0341 \\
\hline
\end{tabular}

In this research work, the hypothesis of isothermal conditions in the fluid were considered, implementing a constant value of the fluid dynamic viscosity to assess its effect on the gear transmission dynamics. Nevertheless, in highspeed range (higher than $6000 \mathrm{rpm}$ ), the thermal effect could be of relevance, and therefore, the results must be treated carefully.

\section{Results and discussion}

In this section, the dynamic transmission error $(D T E)$ of the four torque considered scenarios is presented for the six hydrodynamic force formulations implemented. Specifically, the DTE were calculated during one thousand meshing cycles for each pinion speed, showing the last ten of each pinion speed in the same figure and observing the DTE mean value and deviation in the different pinion speeds simulated. 
Moreover, the root mean square (RMS) value of the DTE is shown for the pinion speed range $(\Omega=500: 100: 9000 \mathrm{rpm})$, assessing in this way the discrepancies among formulations. Subsequently, a deeper analysis of the speed on which formulations differ is also presented.

\subsection{Scenario 1: Without external torque}

In Figure 3, the DTE is shown when there was no torque applied.

From the figure, higher oscillations are observed with the more viscous oil temperature $\left(T_{i n}=40^{\circ} \mathrm{C}\right)$, since higher lubricant forces are induced than in the lower viscosity case. In this regard, this viscosity parameter affects the whole dynamic behaviour, palliating the oscillation amplitude in high frequencies with the decrement of the viscosity. Moreover, the role of the squeeze effect, in this case scenario, is almost negligible, as there are not discrepancies between formulations that implement the same formulations for the entraining fluid effect. This makes sense, as the squeeze term would be prominent, with respect to the entraining velocity one, when the teeth profiles are closer or there exist impacts between them. In order to appreciate these aspects and the discrepancies among formulations, the RMS value of the DTE is shown in Figure 4.

First thing that can be observed from the RMS values with both oil temperatures is that Sasaki's and Rahnejat's formulations follow a trend which is different from the other four formulations. This means that Martin's consideration is decisive in this case.

Apart from that, at $40^{\circ}$ of inlet temperature, these four formulations present a DTE amplification close to $8000 \mathrm{rpm}$, which is not appreciated in the Sasaki's and Rahnejat's formulations. On the other hand, at the higher temperature, the increment of the oscillation amplitude is observed at $5000 \mathrm{rpm}$ in these four formulations, whilst, with Sasaki's and Rahnejat's, this DTE amplification is appreciated close to $6000 \mathrm{rpm}$. Thus, as concluded above, the viscosity clearly influences the system dynamic behaviour, and therefore, these speed regions where formulations differ must be assessed separately (Figure 5 and 6).

In this respect, at $40^{\circ}, 7900 \mathrm{rpm}$ pinion velocity results were assessed (Figure 5), obtaining that the DTE main frequency is related to the angular rotation $(125 \mathrm{~Hz})$ and there is an harmonic derived from the pinion mesh frequency $\left(18^{*} 125=2250 \mathrm{~Hz}\right)$. Again, Martin's consideration changes the dynamic behaviour, not finding a DTE amplification frequency in Rahnejat's and Sasaki's formulations, whilst in the other four, it does appear. Moreover, 

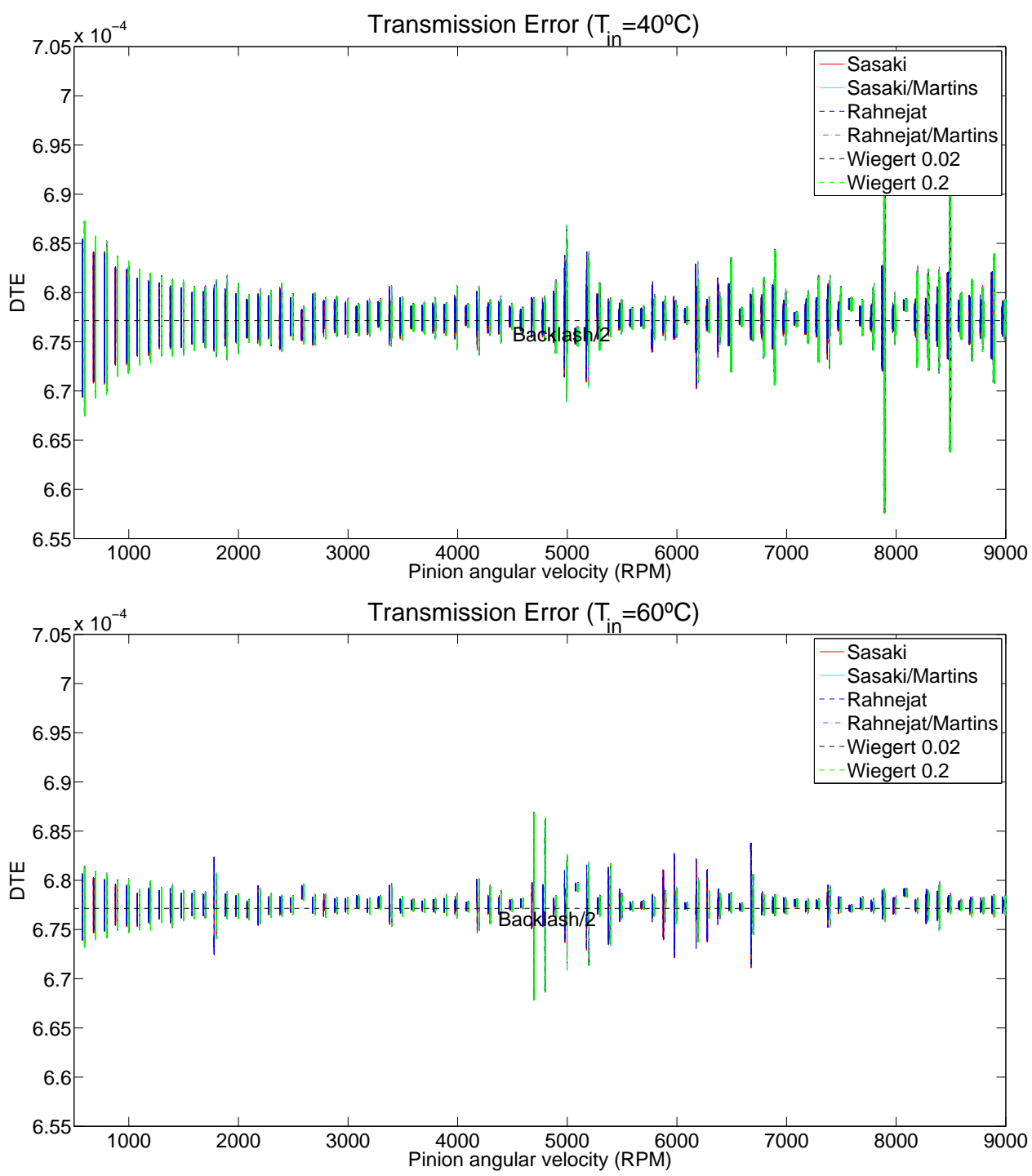

Figure 3: $D T E$ of the considered speed range in stationary conditions with no applied torque for the six hydrodynamic force formulations $\left(T_{i n}=40^{\circ} \mathrm{C}\right.$ above and $T_{i n}=60^{\circ} \mathrm{C}$ below)

the same DTE mean value is obtained for the six formulations, the half of the backlash $\left(6.77 * 10^{-4} \mathrm{rad}\right)$. On the other hand, there is a phase difference between Sasaki's and Rahnejat's and the other four formulations, which is due to a slightly different starting point of the simulation and not related to 
RMS of Transmission Error $\left(\mathrm{T}_{\text {in }}=40^{\circ} \mathrm{C}\right)$

RMS of Transmission Error $\left(\mathrm{T}_{\text {in }}=60^{\circ} \mathrm{C}\right)$
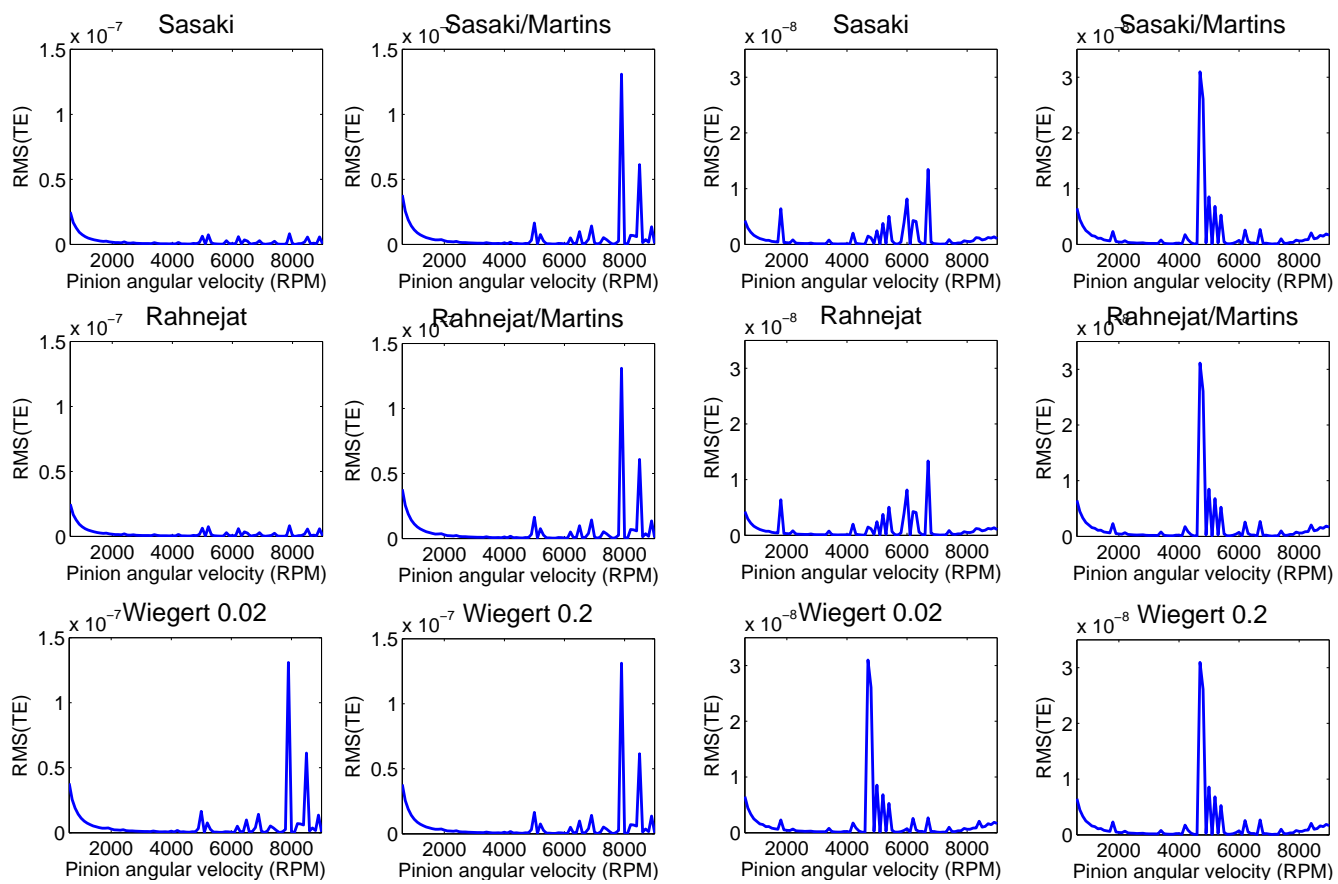

Figure 4: Transmission error RMS value of the speed range considered in stationary conditions without applied torque $\left(T_{i n}=40^{\circ} \mathrm{C}\right.$ on the left and $T_{i n}=60^{\circ} \mathrm{C}$ on the right)
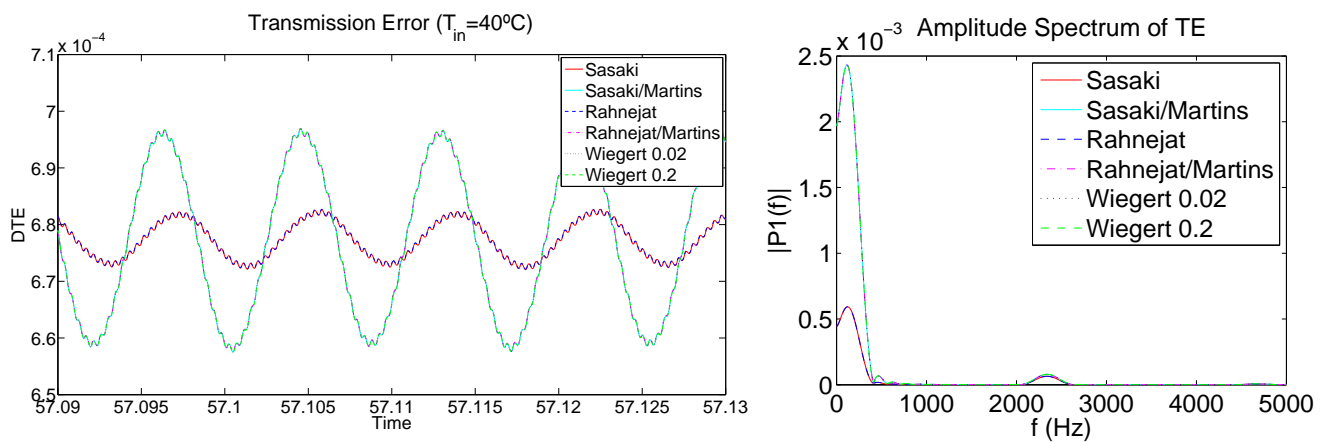

Figure 5: DTE and its spectrum at $7900 \mathrm{rpm}$ without applied torque $\left(T_{i n}=40^{\circ} \mathrm{C}\right)$

the formulations. This fact happens in the subsequent scenarios for the same reason, thus, for the sake of brevity, the same idea is not being repeated.

At $60^{\circ}, 4700 \mathrm{rpm}$ pinion velocity results were assessed (Figure 6), finding 

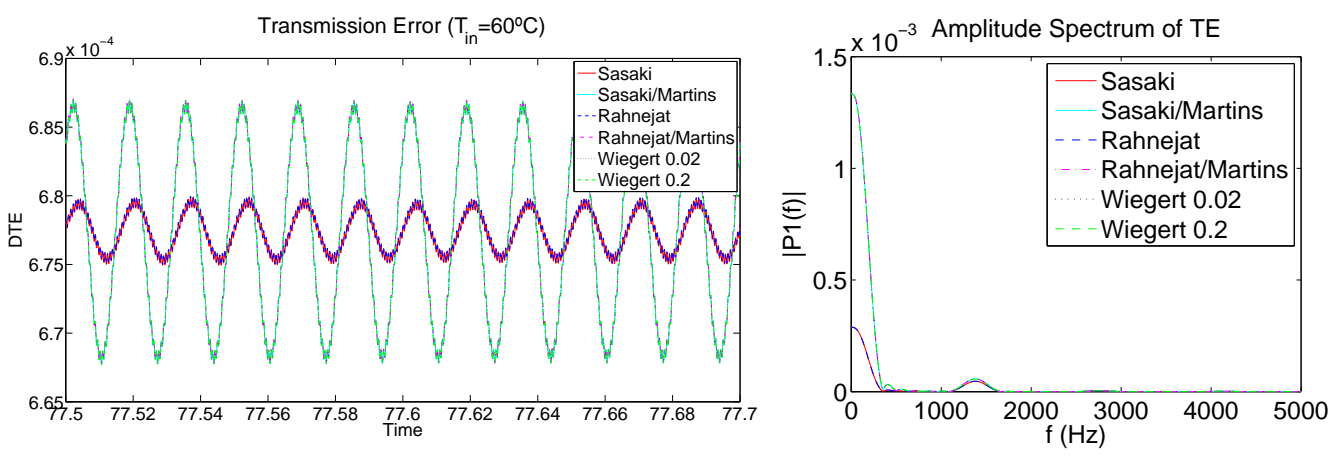

Figure 6: $D T E$ and its spectrum at $4700 \mathrm{rpm}$ without applied torque $\left(T_{i n}=60^{\circ} \mathrm{C}\right)$

that the DTE main frequency is related to the angular rotation $(78 \mathrm{~Hz})$ and there is an harmonic derived from the pinion mesh frequency $\left(18^{*} 78=1404\right.$ $\mathrm{Hz}$ ). Again, Martin's consideration changes the dynamic behaviour, not obtaining a DTE amplification frequency in Rahnejat's and Sasaki's formulations, whilst in the other four, it does appear. Moreover, the same DTE mean value is obtained for the six formulations, the half of the backlash.

\subsection{Scenario 2: Petrov's torque}

In Figure 7, the DTE is shown when Petrov's formulation torque was applied as external load.

From the figure, a similar behaviour as in the first scenario is observed but with a distortion of the DTE mean value, which, in this case, is further from the half-backlash position. This distortion is higher in the low viscosity case because of the lubricant forces, which are smaller with the viscosity decrement. It is also observed that the entraining fluid effect is predominant in this scenario since Sasaki's and Rahnejat's follows a different trend as the other four formulations. Furthermore, the higher oscillations are observed with the more viscous oil temperature $\left(T_{i n}=40^{\circ} \mathrm{C}\right)$ with a similar amplitude as in the first scenario, affecting this viscosity parameter the whole dynamic behaviour, palliating the high-frequency amplitudes with the viscosity decrement. In order to appreciate these facts, the DTE RMS value is shown in Figure 8.

The RMS values show that, with both oil temperatures, Sasaki's and Rahnejat's formulations follow a trend which is different from the other four formulations. This means that Martin's consideration is decisive in order to correctly simulate the dynamic behaviour under rattle conditions (low 

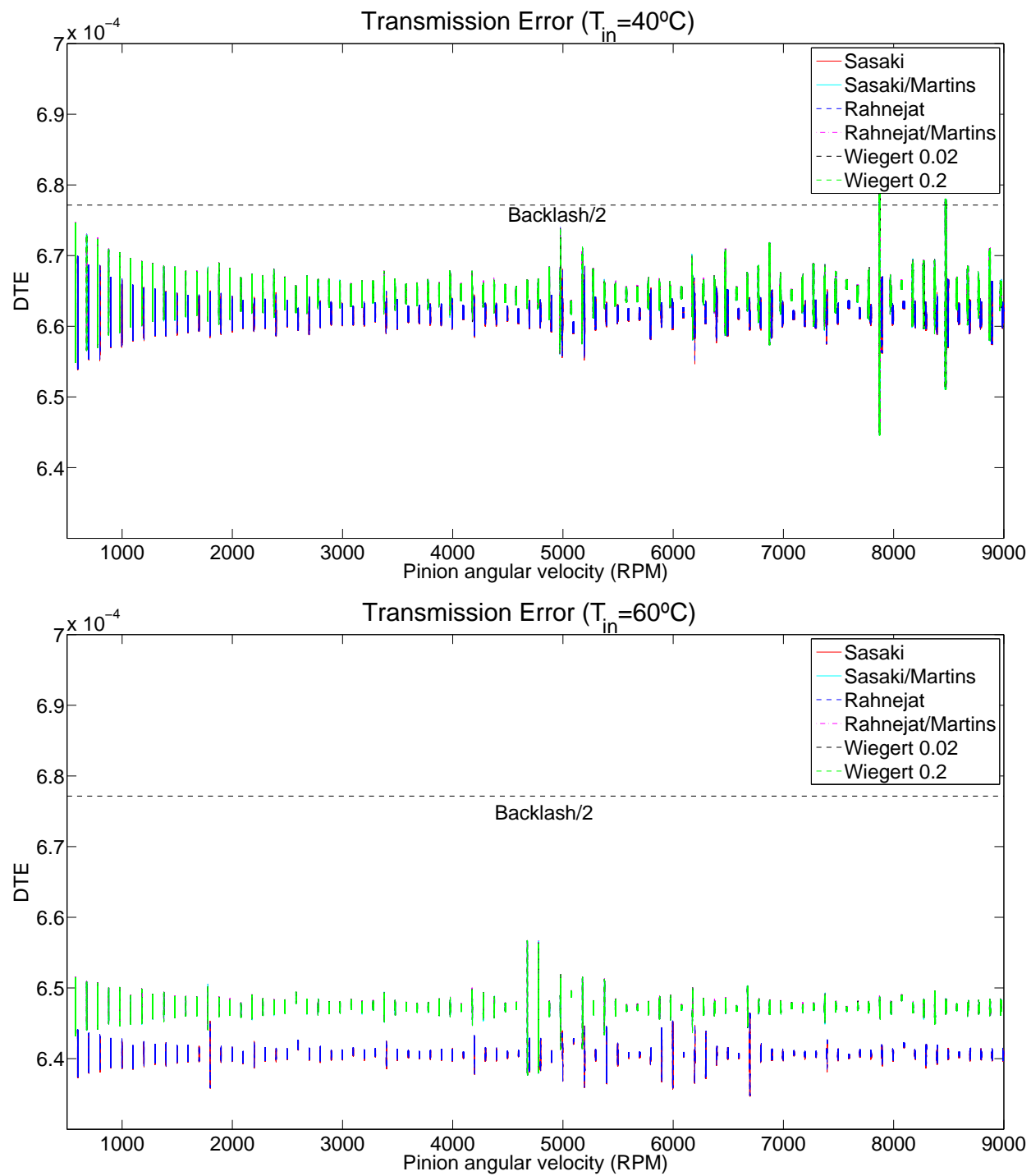

Figure 7: DTE of the speed range considered in stationary conditions with Petrov's torque for the six hydrodynamic force formulations $\left(T_{i n}=40^{\circ} \mathrm{C}\right.$ above and $T_{i n}=60^{\circ} \mathrm{C}$ below $)$

loads). This trend happens in the following scenarios, therefore, for the sake of brevity, it is not being repeated in the subsequent sections.

Furthermore, at the lower temperature, these four formulations present a DTE amplification close to $8000 \mathrm{rpm}$, which is not appreciated in the Sasaki's and Rahnejat's formulations. At $T_{i n}=60^{\circ} \mathrm{C}$, the increment of the oscillation 
RMS of Transmission Error $\left(\mathrm{T}_{\text {in }}=40^{\circ} \mathrm{C}\right)$

RMS of Transmission Error $\left(\mathrm{T}_{\text {in }}=60^{\circ} \mathrm{C}\right)$
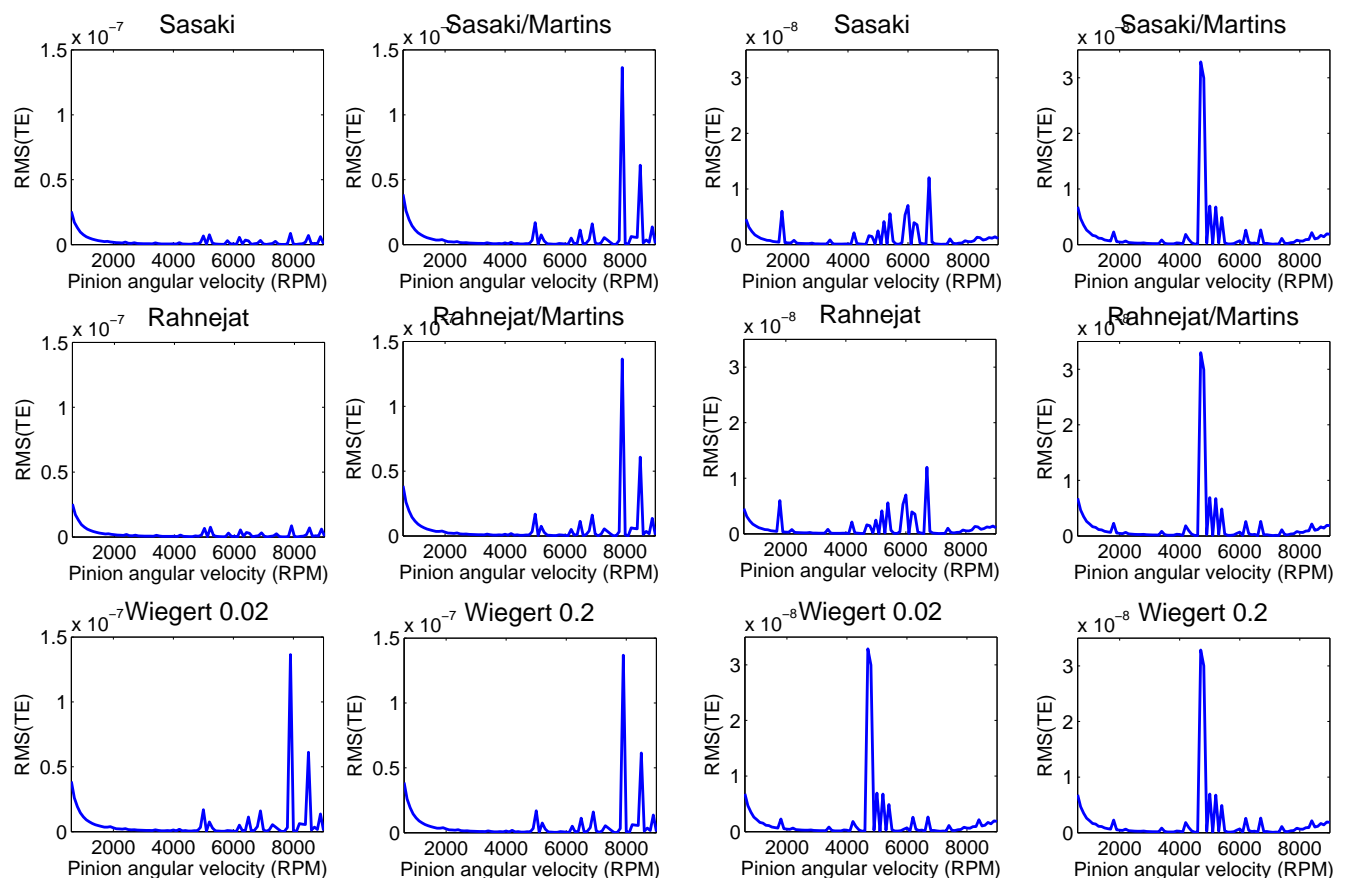

Figure 8: Transmission error RMS value of the considered speed range in stationary conditions with Petrov's torque $\left(T_{i n}=40^{\circ} \mathrm{C}\right.$ on the left and $T_{i n}=60^{\circ} \mathrm{C}$ on the right $)$

amplitude is observed at $5000 \mathrm{rpm}$ in these four formulations, however, with Sasaki's and Rahnejat's, this DTE amplification is appreciated close to 6000 rpm. Hence, the viscosity clearly influences the system dynamic behaviour. The speed regions where formulations differ are to be assessed separately in order to comprehend this performance (Figure 9 and 10).

At $40^{\circ}$ and $7900 \mathrm{rpm}$, the DTE main frequency is related to the angular rotation $(125 \mathrm{~Hz})$, being the amplitude four times greater for the four formulations that implement Martin's consideration than Rahnejat's and Sasaki's ones. There is an harmonic derived from the pinion mesh frequency $\left(18^{*} 125=2250 \mathrm{~Hz}\right)$, which is observed when the six formulations were implemented. If the results are compared with the obtained in first scenario, the main difference is the distortion of the DTE mean value, since the oscillation amplitude is similar although a variable external torque was applied.

At $60^{\circ}$ and $4700 \mathrm{rpm}$, the DTE main frequency is related to the angular rotation $(78 \mathrm{~Hz})$, being the amplitude five times greater for the four formu- 

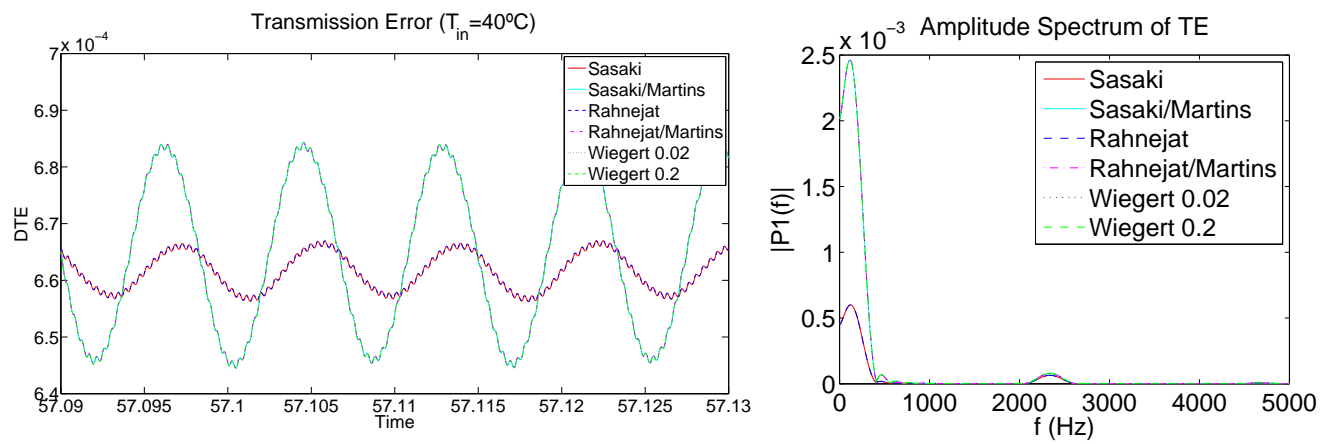

Figure 9: $D T E$ and its spectrum at $7900 \mathrm{rpm}$ Petrov's torque $\left(T_{i n}=40^{\circ} \mathrm{C}\right)$
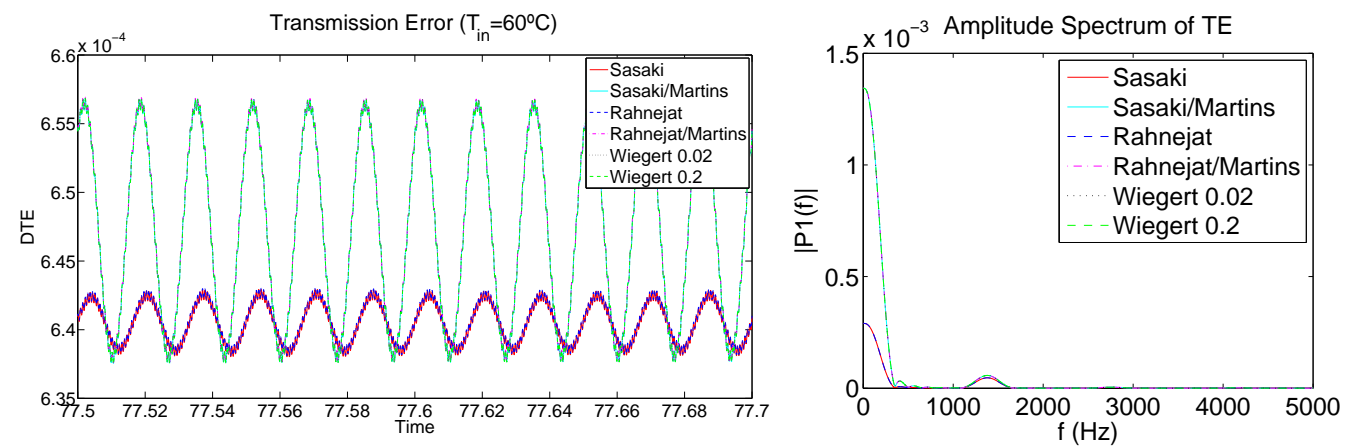

Figure 10: $D T E$ and its spectrum at $4700 \mathrm{rpm}$ Petrov's torque $\left(T_{i n}=60^{\circ} \mathrm{C}\right)$

lations that implement Martin's consideration than Rahnejat's and Sasaki's ones. Moreover, there is an harmonic derived from the pinion mesh frequency $(18 * 78=1404 \mathrm{~Hz})$ and observed for the six formulations. When comparing with first scenario results, a distortion of the DTE mean value is observed for the six formulations, being this distortion even greater for Sasaki's and Rahnejat's formulations.

\subsection{Scenario 3: $0.1 \mathrm{Nm}$ Torque}

The DTE is presented in Figure 11, when a constant external torque of $0.1 \mathrm{Nm}$ was applied and two oil viscosities were considered.

From the figure, the DTE tends to move forward to the half-backlash position with the increment of the pinion speed. This fact is quicker in the high viscosity case $\left(T_{i n}=40^{\circ} \mathrm{C}\right)$, since the lubrication force is greater than in the low viscosity case, where this tendency is observed to be smoother. 

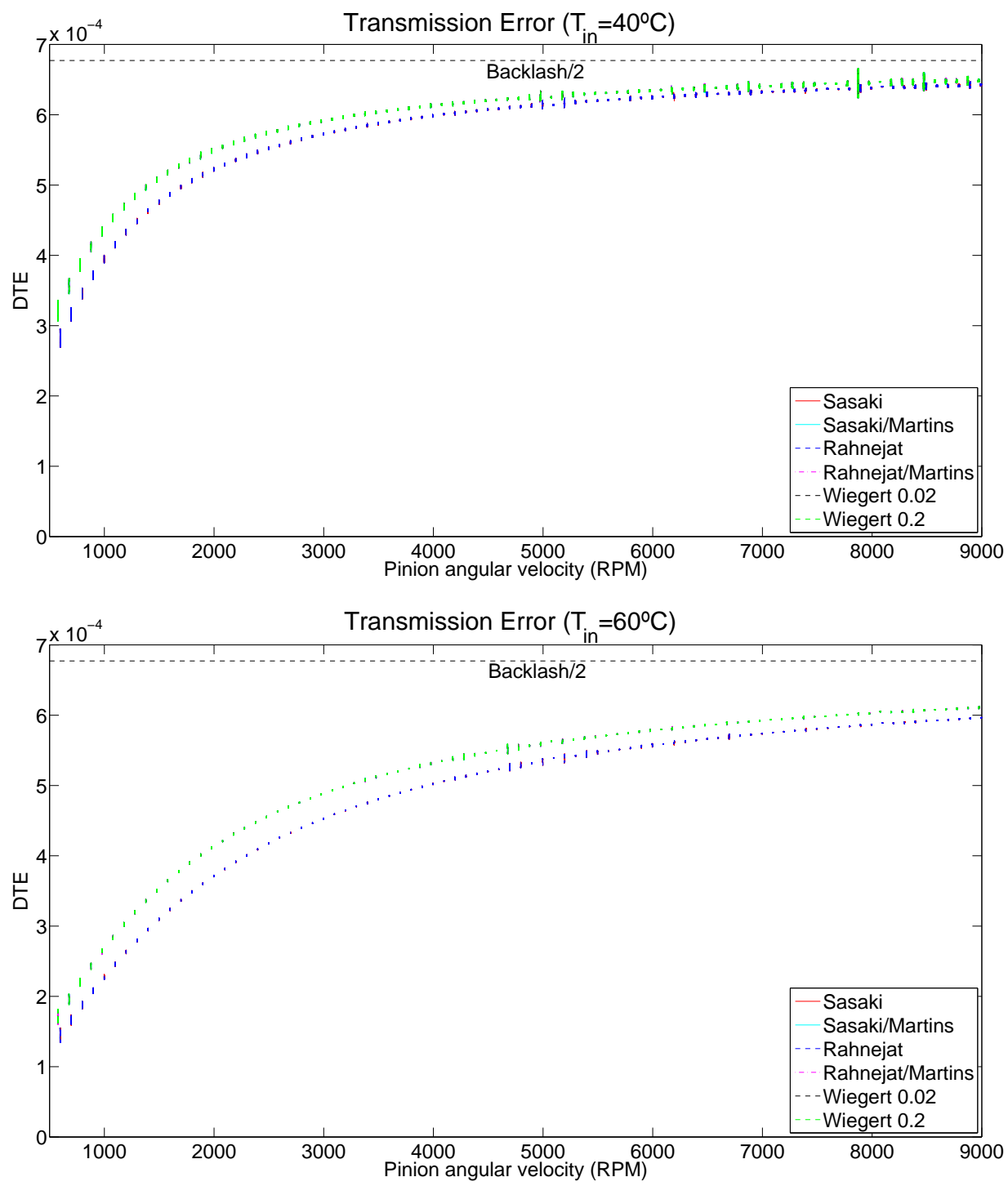

Figure 11: DTE of the considered speed range in stationary conditions with $0.1 \mathrm{Nm}$ torque for the six hydrodynamic force formulations $\left(T_{i n}=40^{\circ} \mathrm{C}\right.$ above and $T_{\text {in }}=60^{\circ} \mathrm{C}$ below $)$

There is also higher distortion between Sasaki's and Rahnejat's formulations with respect to the other four in the lower viscosity case, which is due to Martin's consideration in the entraining velocity effect. In the pinion speed range between 500 and $1000 \mathrm{rpm}$, this distortion is reduced because of the squeeze effect when the profiles are closer than in higher speeds. In Figure 
12, these aspects can be assessed by the DTE RMS values.

RMS of Transmission Error $\left(\mathrm{T}_{\text {in }}=40^{\circ} \mathrm{C}\right)$

RMS of Transmission Error $\left(\mathrm{T}_{\text {in }}=60^{\circ} \mathrm{C}\right)$
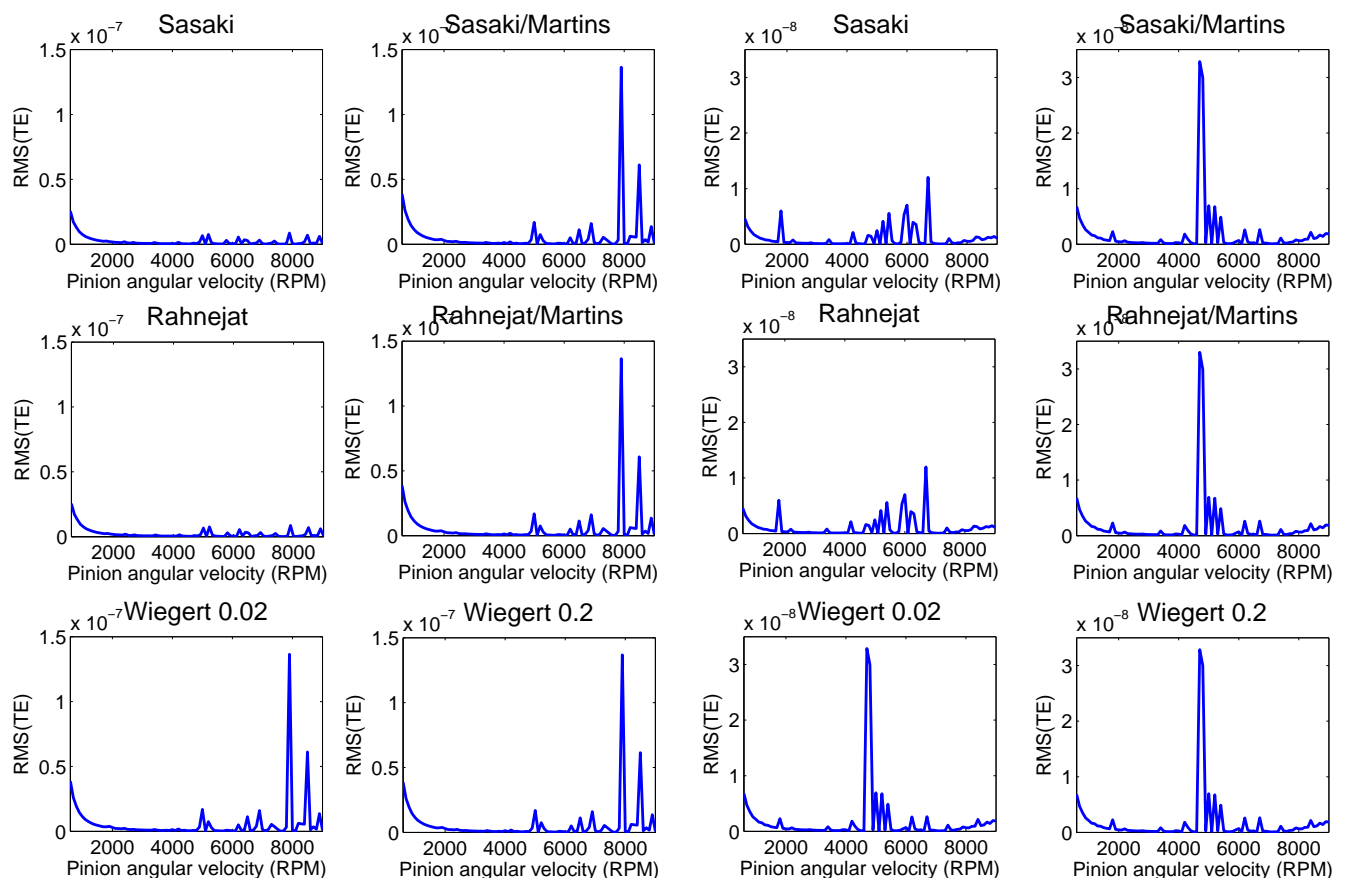

Figure 12: Transmission error RMS value of the speed range considered in stationary conditions with $0.1 \mathrm{Nm}$ torque $\left(T_{i n}=40^{\circ} \mathrm{C}\right.$ on the left and $T_{i n}=60^{\circ} \mathrm{C}$ on the right)

At $40^{\circ}$ of inlet temperature, Sasaki's and Rahnejat's formulations do not present a DTE amplification close to $8000 \mathrm{rpm}$ whilst the other four formulations do, following a similar trend as in both previous scenarios. At the higher temperature, a DTE amplification is observed at $5000 \mathrm{rpm}$ for these four formulations, whilst, with Sasaki's and Rahnejat's, it is close to 6000 rpm. These speed regions are assessed next by Figure 13 and 14 .

The main DTE frequency corresponds to the angular rotation, which value is $125 \mathrm{~Hz}$, at $40^{\circ}$ of the oil and $7900 \mathrm{rpm}$ of pinion speed (Figure 13). When Sasaki's and Rahnejat's formulations were implemented, the value corresponding to this frequency is a fifth of the value obtained with the other four formulations. Apart from that, an harmonic related to the pinion mesh frequency was obtained at $2250 \mathrm{~Hz}$ for the six formulations.

At $60^{\circ}$ and $4700 \mathrm{rpm}$, the angular rotation frequency is $78 \mathrm{~Hz}$, which correspond to the main DTE frequency, as shown in Figure 14. In this case, 

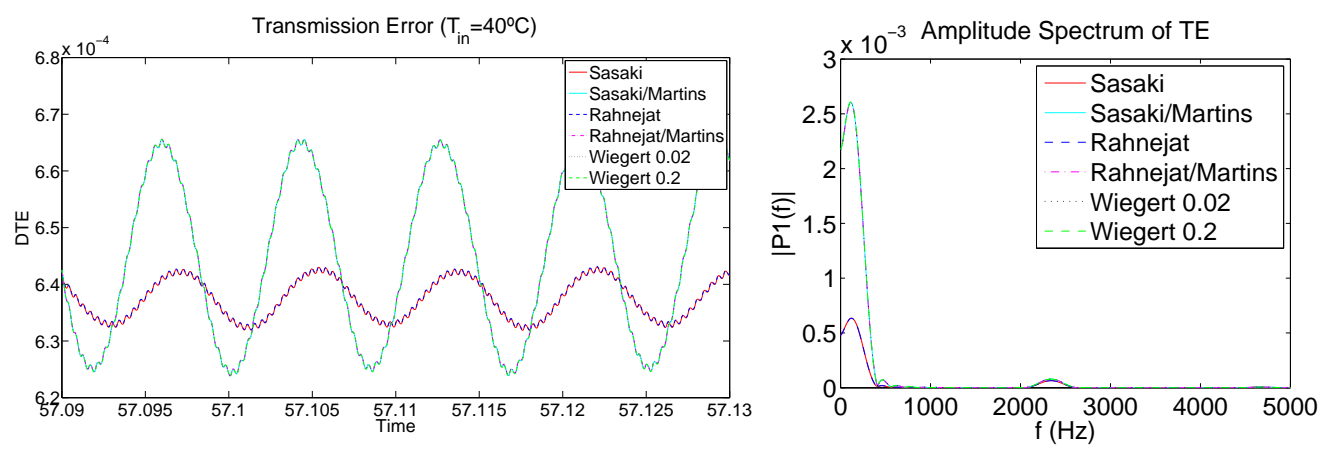

Figure 13: DTE and its spectrum at $7900 \mathrm{rpm}$ Petrov's torque $\left(T_{\text {in }}=40^{\circ} \mathrm{C}\right)$
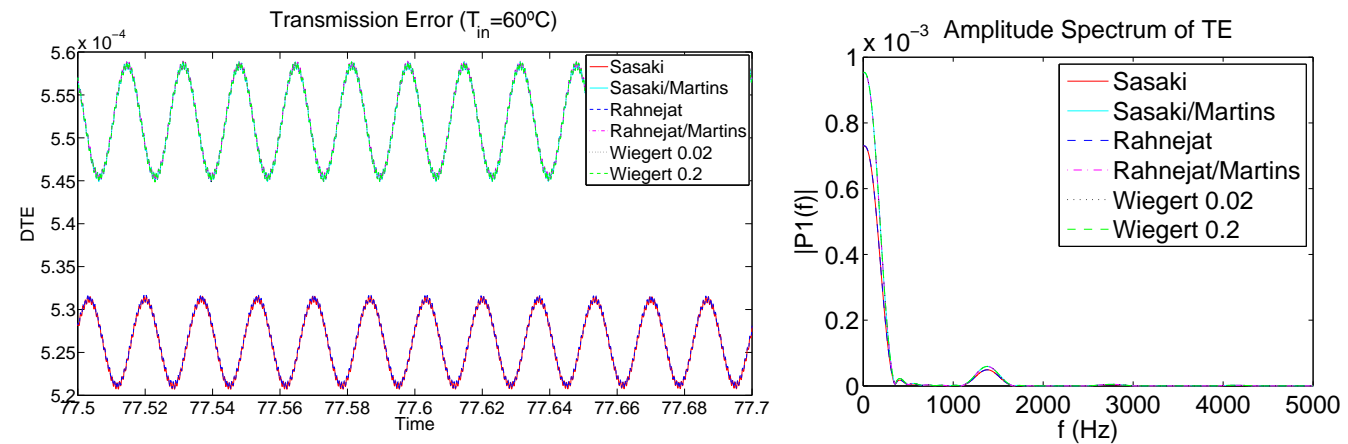

Figure 14: $D T E$ and its spectrum at $4700 \mathrm{rpm}$ Petrov's torque $\left(T_{\text {in }}=60^{\circ} \mathrm{C}\right)$

the difference between Sasaki's and Rahnejat's with respect to the other four is not so appreciated by the DTE spectrum, since the main difference resides in the DTE mean value, which is not represented by the RMS values of the signals. Moreover, an harmonic at $1400 \mathrm{~Hz}$ was obtained, which is related to the pinion mesh frequency.

\subsection{Scenario 4: $0.1 N m+$ Petrov's torque}

In Figure 7, the DTE is shown when Petrov's formulation was added to $0.1 \mathrm{Nm}$ external torque.

From the figure, similarly as in the previous scenario, the DTE tends to approach the half-backlash position when the pinion speed increases. This effect is emphasised in the high viscosity case, as the equivalent lubricant damping is greater than at $T_{i n}=60^{\circ} \mathrm{C}$. Moreover, the difference between Sasaki's and Rahnejat's and the other four formulations is higher in the low 

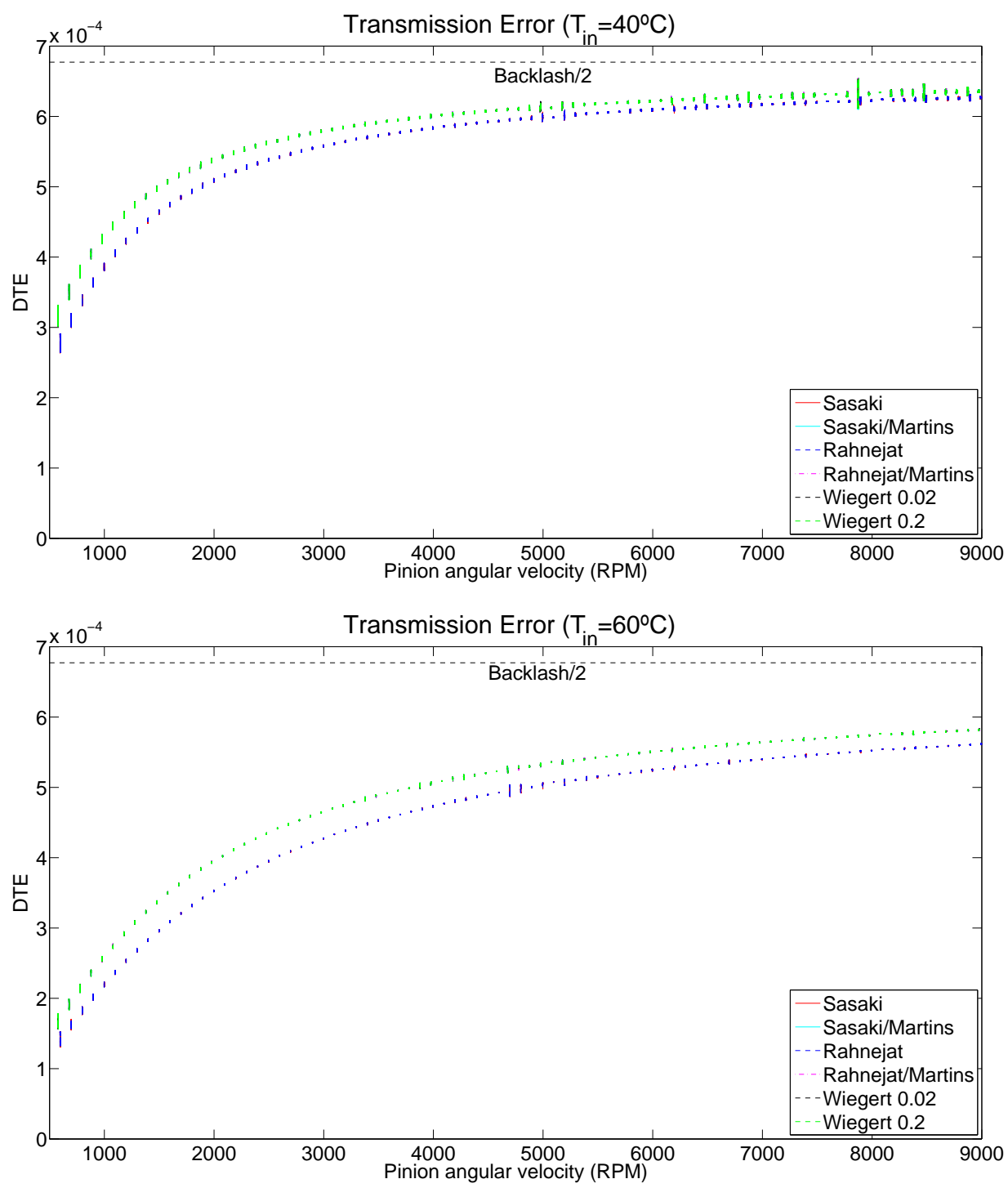

Figure 15: DTE of the speed range considered in stationary conditions with constant and variable torque for the six hydrodynamic force formulations $\left(T_{i n}=40^{\circ} \mathrm{C}\right.$ above and $T_{\text {in }}=60^{\circ} \mathrm{C}$ bellow)

viscosity case, which is related to Martin's consideration and therefore to the entraining fluid effect. This fact is not so noticeable between 500 and 1000 rpm, which is explained by the role of the squeeze effect as the profiles are closer than in higher speed values. These discrepancies among formulations 
are explained by Figure 16 where the DTE RMS values are presented.

RMS of Transmission Error $\left(\mathrm{T}_{\text {in }}=40^{\circ} \mathrm{C}\right)$
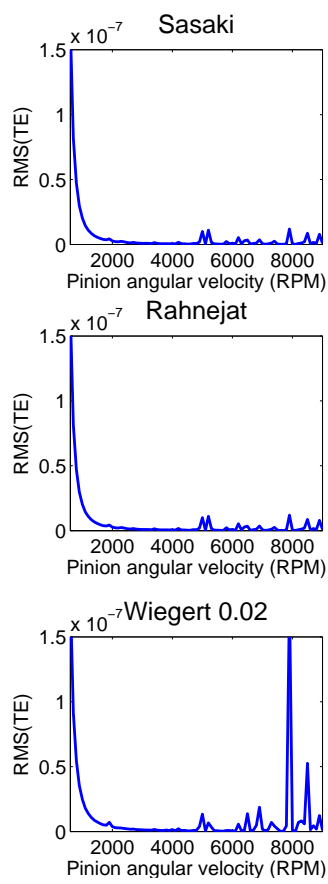
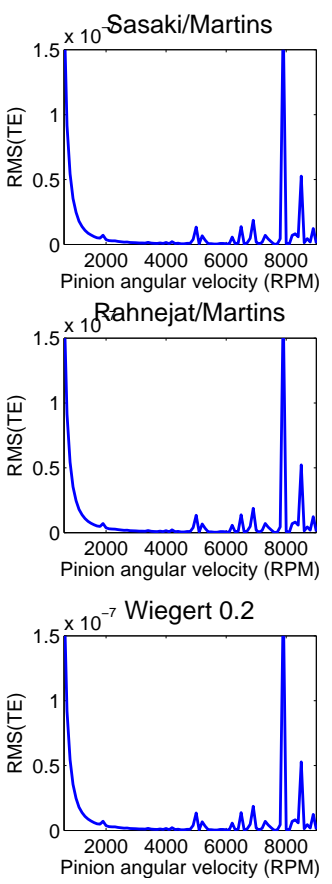

RMS of Transmission Error $\left(\mathrm{T}_{\text {in }}=60^{\circ} \mathrm{C}\right)$
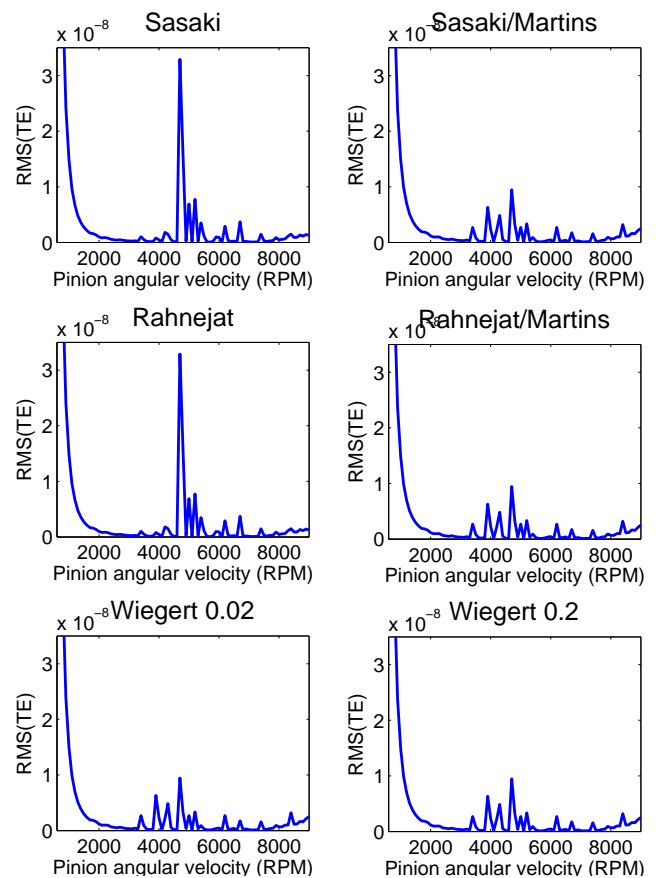

Figure 16: Transmission error RMS value of the speed range considered in stationary conditions with constant and variable torque $\left(T_{i n}=40^{\circ} \mathrm{C}\right.$ on the left and $T_{i n}=60^{\circ} \mathrm{C}$ on the right)

At $40^{\circ}$ of inlet temperature, the $D T E$ obtained by the four formulations presents a DTE amplification close to $8000 \mathrm{rpm}$, whilst the DTE calculated with Sasaki's and Rahnejat's formulations does not. At $40^{\circ}$ of inlet temperature, this DTE amplification is observed at $5000 \mathrm{rpm}$ in Sasaki's and Rahnejat's whilst in the four formulations is not so well apprecieated. This is the contrary behaviour observed in the three preceding scenarios. In order to assess this behaviour, Figure 17 and 18 presents the DTE at these speeds.

At $40^{\circ}$ and $7900 \mathrm{rpm}$ pinion speed, the same behaviour as in previous scenarios was obtained. The DTE main frequency due to the angular rotation was obtained at $125 \mathrm{~Hz}$ and an harmonic at $2250 \mathrm{~Hz}$ derived from the pinion mesh frequency.

However, at $60^{\circ}$ and $4700 \mathrm{rpm}$, the contrary behaviour to the three preceding scenarios was obtained, where the DTE main frequency related to 

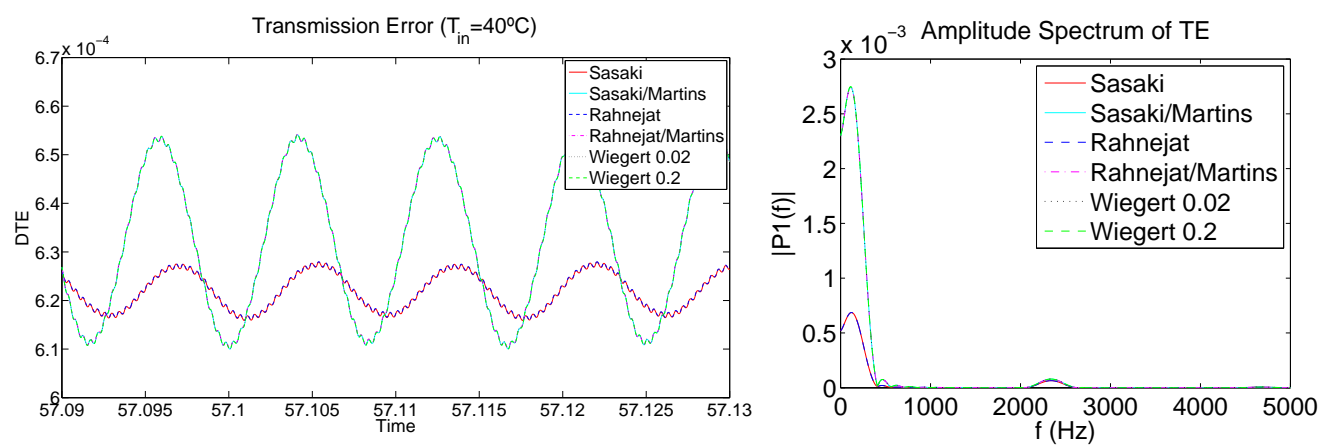

Figure 17: DTE and its spectrum at $7900 \mathrm{rpm}$ with constant and variable torque $\left(T_{\text {in }}=\right.$ $\left.40^{\circ} \mathrm{C}\right)$
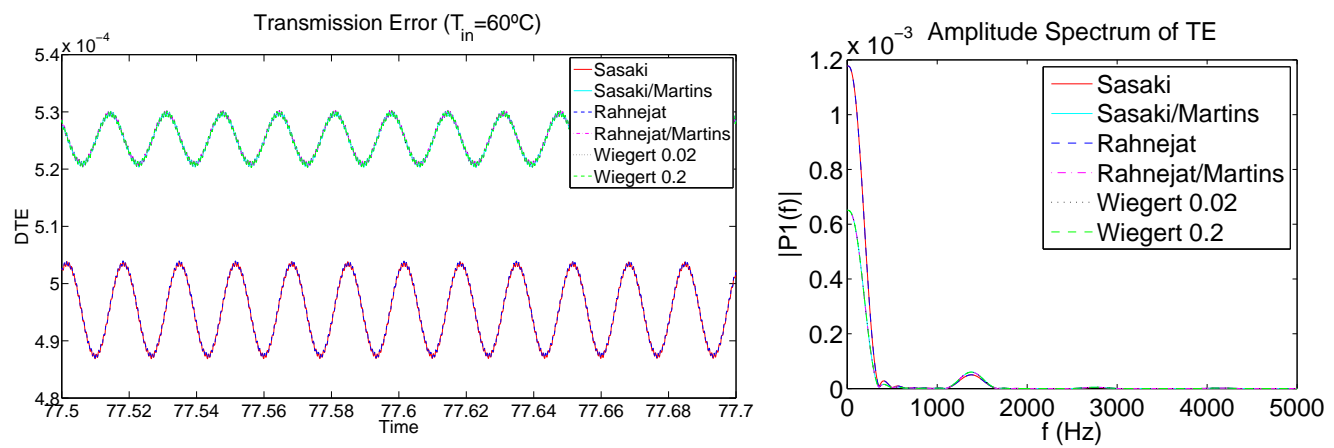

Figure 18: DTE and its spectrum at $4700 \mathrm{rpm}$ with constant and variable torque $\left(T_{\text {in }}=\right.$ $\left.60^{\circ} \mathrm{C}\right)$

the angular rotation $(78 \mathrm{~Hz})$ was higher for Sasaki's and Rahnejat's than for the other four formulations. This results from the change in the dynamic behaviour due to the variable torque applied.

\subsection{Comparison among torque scenarios}

With Figures 19, 20, 21 and 22, the influence of the external torque on the dynamic behaviour of the system and on the six formulations is to be assessed.

In Figure 19, the DTE error is presented for the four torque scenarios, when the six formulations were considered in the higher viscosity case. It is concluded by this figure that the higher the torque, the further the teeth is from the half-backlash position. This distance is reduced with the increment of the pinion speed. In order to appreciate the difference between 
formulations and torque scenarios, the DTE RMS value of these signals are presented in Figure 20.
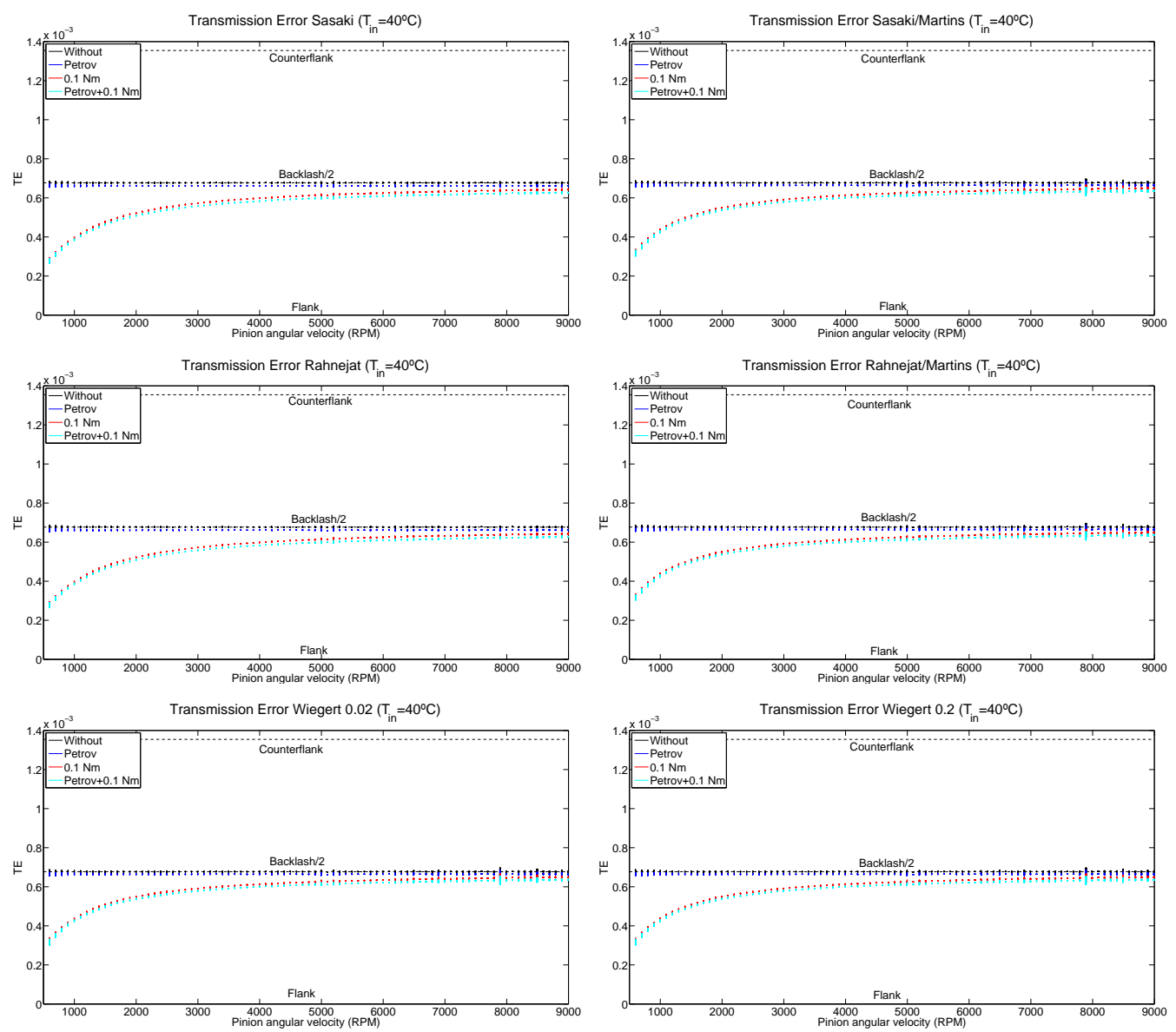

Figure 19: DTE under the four torque scenarios and for the six hydrodynamic force formulations $\left(T_{i n}=40^{\circ} \mathrm{C}\right)$

From the figure, regarding the torque influence, a change of the behaviour at low speeds is appreciated with higher torques. With respect to the formulations comparison, Sasaki's and Rahnejat's follows a different trend than the other four. This means that the fluid entraining effect is more prominent than the squeeze one in the analysed cases, and therefore, that Martin's consideration is of crucial importance in order to assess rattle phenomenon.

In Figure 21, the DTE error is presented for the four torque scenarios, when the six formulations were considered in the lower viscosity case. As 
RMS of Transmission Error $\left(\mathrm{T}_{\text {in }}=40^{\circ} \mathrm{C}\right)$
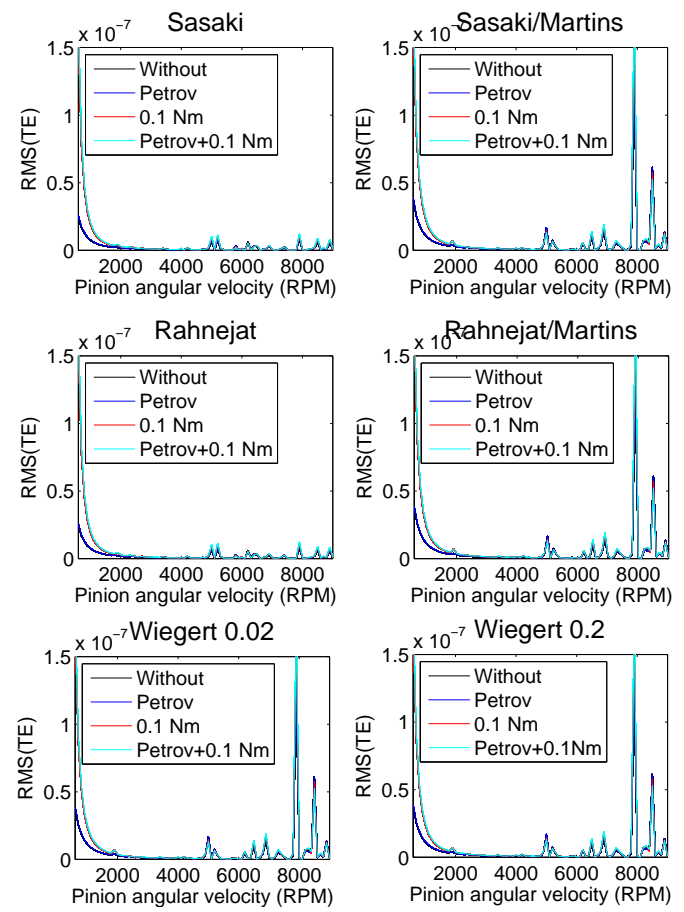

Figure 20: RMS value of the $D T E$ under the four torque scenarios $\left(T_{i n}=40^{\circ} \mathrm{C}\right)$

before, the higher the torque, the further the teeth is from the half-backlash position. This distance is reduced with the increment of the pinion speed. Comparing with the higher viscosity case, it can be concluded that the lower the viscosity, more speed is required to reach this half-backlash position, since the lubricant forces are greater with high viscosities and push harder the tooth to this position.

In order to appreciate the difference between formulations and torque scenarios, the DTE RMS value of these signals are presented in Figure 20.

From the figure, regarding the torque influence, besides the change of the behaviour at low speeds with higher torques, there are significant modifications in the dynamic behaviour close to $5000 \mathrm{rpm}$. Whilst in the results obtained when Sasaki's and Rahnejat's formulations were implemented, there exist a DTE amplification with the increment of torque at $4700 \mathrm{rpm}$, the contrary occurs in the other four formulations, decreasing the value of the DTE RMS with the increment of the torque. From this fact, it is concluded that 

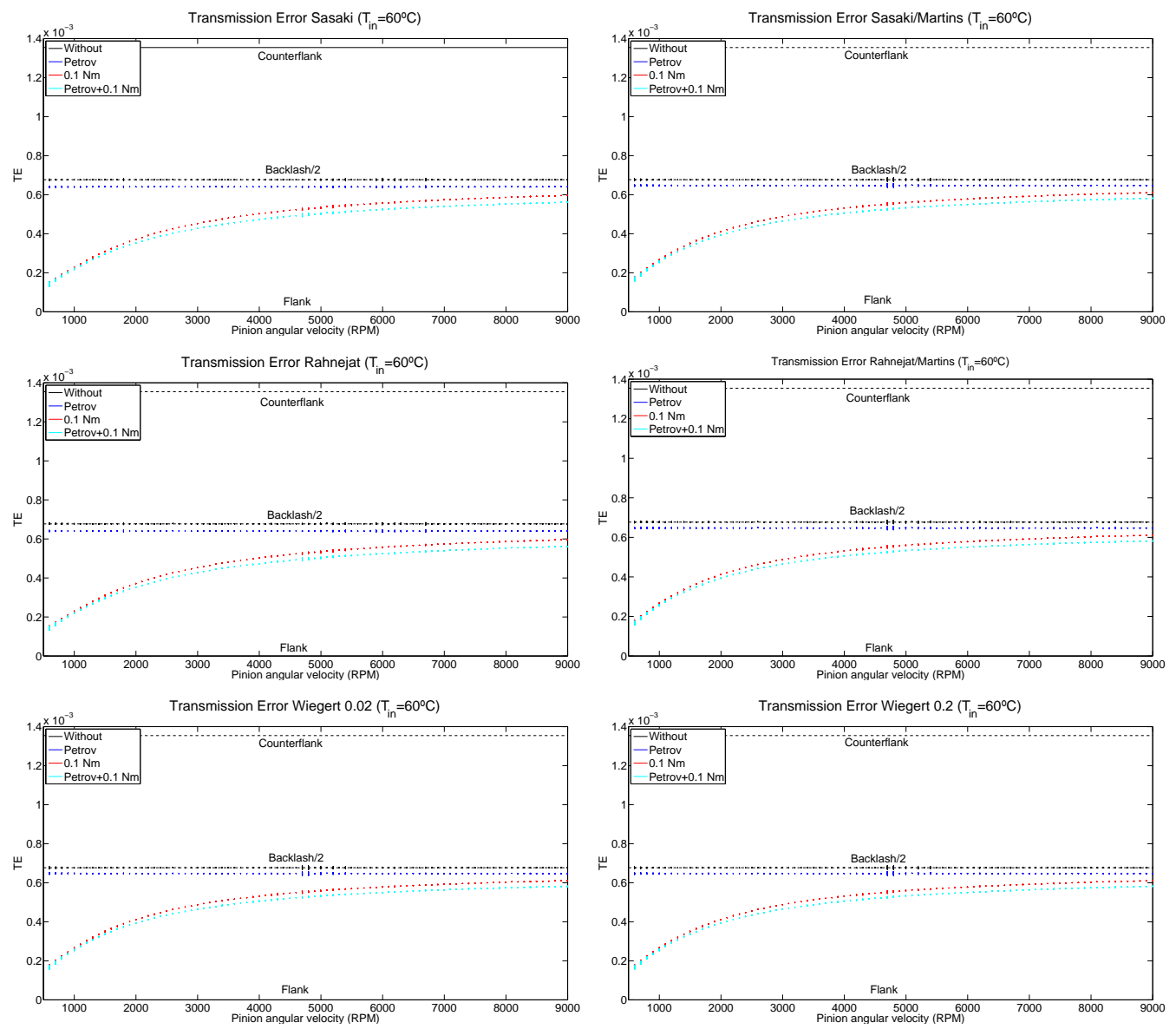

Figure 21: $D T E$ under the four torque scenarios and for the six hydrodynamic force formulations $\left(T_{i n}=60^{\circ} \mathrm{C}\right)$

Martin's consideration makes the difference among formulations and also that the torque influence on the dynamic behaviour becomes of importance with the decrement of the viscosity, which is not the case for high viscosities, where the torque influence is less significant.

\section{Conclusions}

In this paper, the dynamic behaviour of low-loaded gear transmissions were assessed under four torque scenarios, using six formulations which considers both fluid effects to calculate the hydrodynamic forces. In this regard, gear transmission models previously developed by the authors were used, 
RMS of Transmission Error $\left(\mathrm{T}_{\text {in }}=60^{\circ} \mathrm{C}\right)$
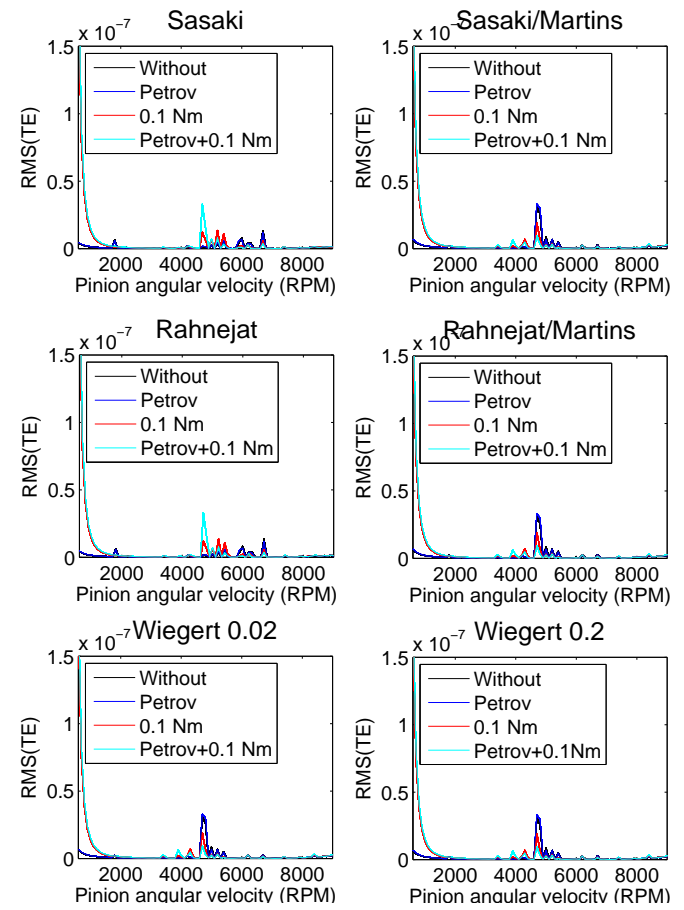

Figure 22: RMS value of the $D T E$ under the four torque scenarios $\left(T_{i n}=60^{\circ} \mathrm{C}\right)$

making special emphasis on the influence of the fluid viscosity on the system dynamic behaviour.

Based on the obtained results, it can be concluded that, under these operating conditions, the effect of lubricant entrance in the contact area plays a decisive role in the dynamic behaviour, becoming the squeeze effect important when the profile teeth were closer. In this regard and comparing results obtained implementing the six formulations, Sasaki's and Rahnejat's formulations follow a different trend than the other four. This means that the fluid entraining effect is more prominent than the squeeze one in the analysed cases, and therefore, that Martin's consideration makes the difference among formulations and is therefore of crucial importance in order to assess rattle phenomenon.

Regarding the torque influence on the dynamic behaviour, the applied torque becomes of importance with the decrement of the viscosity, changing the DTE amplification regions, which is not the case for high viscosities, where the torque influence is less significant. Thus, the role of the oil in 
terms of the viscosity effect on the dynamic behaviour is higher than the external torque effect.

As future work, two lines are proposed; studying the thermal effects on the dynamics of the gear transmission as well as the experimental validation of the analysed formulations.

Acknowledgments This work has been supported by project DPI201785390-P funded by the Spanish Ministry of Science and Technology.

[1] M. Ankouni, A.A. Lubrecht, and P. Velex. Modelling of damping in lubricated line contacts - applications to spur gear dynamic simulations. Proceedings of the Institution of Mechanical Engineers, Part C: Journal of Mechanical Engineering Science, 230(7-8):1222-1232, 2015.

[2] R. Brancati, E. Rocca, and R. Russo. An analysis of the automotive driveline dynamic behaviour focusing on the influence of the oil squeeze effect on the idle rattle phenomenon. Journal of Sound and Vibration, 303(3-5):858-872, 2007.

[3] F. Chaari, M.S. Abbes, F.V. Rueda, A.F. del Rincon, and M. Haddar. Analysis of planetary gear transmission in non-stationary operations. Frontiers of Mechanical Engineering, 8(1):88-94, 2013.

[4] W. Chong and M. De La Cruz. Elastoplastic contact of rough surfaces: A line contact model for boundary regime of lubrication. Meccanica, 49(5):1177-1191, 2014.

[5] M. De La Cruz, W. Chong, M. Teodorescu, S. Theodossiades, and H. Rahnejat. Transient mixed thermo-elastohydrodynamic lubrication in multi-speed transmissions. Tribology International, 49:17-29, 2012.

[6] M. De la Cruz, S. Theodossiades, H. Rahnejat, and P. Kelly. Analysis of non-linear impact dynamics in automotive transmissions: Gear rattle. In Proceedings of the 7th International Conference on Engineering Computational Technology, 2010.

[7] A. Diez-Ibarbia, A. Fernandez-del Rincon, A. de Juan, M. Iglesias, P. Garcia, and F. Viadero. Frictional power losses on spur gears with tip reliefs. the load sharing role. Mechanism and Machine Theory, 112:240$254,2017$. 
[8] A. Diez-Ibarbia, A. Fernandez-del Rincon, A. de Juan, M. Iglesias, P. Garcia, and F. Viadero. Frictional power losses on spur gears with tip reliefs. the friction coefficient role. Mechanism and Machine Theory, 121:15-27, 2018.

[9] C.R. Evans and University of Cambridge. Measurement and Mapping of the Rheological Properties of Elastohydrodynamic Lubricants. University of Cambridge, 1983.

[10] A. Fernandez-Del-Rincon, A. Diez-Ibarbia, and S. Theodossiades. Gear transmission rattle: Assessment of meshing forces under hydrodynamic lubrication. Applied Acoustics, 144:85-95, 2019.

[11] A. Fernandez-del Rincon, P. Garcia, A. Diez-Ibarbia, A. de Juan, M. Iglesias, and F. Viadero. Enhanced model of gear transmission dynamics for condition monitoring applications: Effects of torque, friction and bearing clearance. Mechanical Systems and Signal Processing, $85: 445-467,2017$.

[12] A. Fernandez del Rincon, M. Iglesias, A. de Juan, A. Diez-Ibarbia, P. Garcia, and F. Viadero. Gear transmission dynamics: Effects of index and run out errors. Applied Acoustics, 108:63-83, 2016.

[13] P. Flores. Kinematics and dynamics of mechanical systems with lubricated revolute joints: The infinitely-short journal-bearing approach. International Review of Civil Engineering, 6(5):117-123, 2015.

[14] C. Gill-Jeong. Analysis of the nonlinear behavior of gear pairs considering hydrodynamic lubrication and sliding friction. Journal of Mechanical Science and Technology, 23(8):2125-2137, 2009.

[15] R. Guilbault, S. Lalonde, and M. Thomas. Nonlinear damping calculation in cylindrical gear dynamic modeling. Journal of Sound and Vibration, 331(9):2110-2128, 2012.

[16] M. Hammami, R. Martins, M.S. Abbes, M. Haddar, and J. Seabra. Axle gear oils: Tribological characterization under full film lubrication. Tribology International, 106:109 - 122, 2017. 
[17] M. Iglesias, A. Fernandez del Rincon, A. de Juan, A. Diez-Ibarbia, P. Garcia, and F. Viadero. Advanced model for the calculation of meshing forces in spur gear planetary transmissions. Meccanica, 50(7):18691894, 2015.

[18] P. Marques, C. Fernandes, R. Martins, and J. Seabra. Efficiency of a gearbox lubricated with wind turbine gear oils. Tribology International, $71: 7-16,2014$.

[19] HM Martin. Lubrication of gear teeth. Engineering (London), 102:119$121,1916$.

[20] E. Mucchi, G. Dalpiaz, and A. Fernandez Del Rincon. Elasto-dynamic analysis of a gear pump-part iv: Improvement in the pressure distribution modelling. Mechanical Systems and Signal Processing, 50-51:193213, 2015.

[21] E. Mucchi, A. Rivola, and G. Dalpiaz. Modelling dynamic behaviour and noise generation in gear pumps: Procedure and validation. Applied Acoustics, 77:99-111, 2014.

[22] C. Nutakor, A. Kłodowski, J. Sopanen, A. Mikkola, and J.I. Pedrero. Planetary gear sets power loss modeling: Application to wind turbines. Tribology International, 105:42-54, 2017.

[23] J.R. Ottewill, S.A. Neild, and R.E. Wilson. Intermittent gear rattle due to interactions between forcing and manufacturing errors. Journal of Sound and Vibration, 321(3-5):913-935, 2009.

[24] J.R. Ottewill, S.A. Neild, and R.E. Wilson. An investigation into the effect of tooth profile errors on gear rattle. Journal of Sound and Vibration, 329(17):3495-3506, 2010.

[25] R. Russo, R. Brancati, and E. Rocca. Experimental investigations about the influence of oil lubricant between teeth on the gear rattle phenomenon. Journal of Sound and Vibration, 321(3-5):647-661, 2009.

[26] T. Sasaki, H. Mori, and N. Okino. Fluid lubrication theory of roller bearing: Part i: Fluid lubrication theory for two rotating cylinders in contact. Journal of Fluids Engineering, Transactions of the ASME, 84(1):166-174, 1962. 
[27] S. Theodossiades, O. Tangasawi, and H. Rahnejat. Gear teeth impacts in hydrodynamic conjunctions promoting idle gear rattle. Journal of Sound and Vibration, 303(3-5):632-658, 2007.

[28] B. Wiegert, H. Hetzler, and W. Seemann. An analytical expression of the normal force of hydrodynamic line contacts under transient conditions. Tribology International, 61:32 - 39, 2013.

[29] B. Wiegert, H. Hetzler, and W. Seemann. A simplified elastohydrodynamic contact model capturing the nonlinear vibration behaviour. Tribology International, 59:79 - 89, 2013.

[30] H. Xu. A novel formula for instantaneous coefficients of sliding friction in gearing. SAE Technical Papers, 2007. 